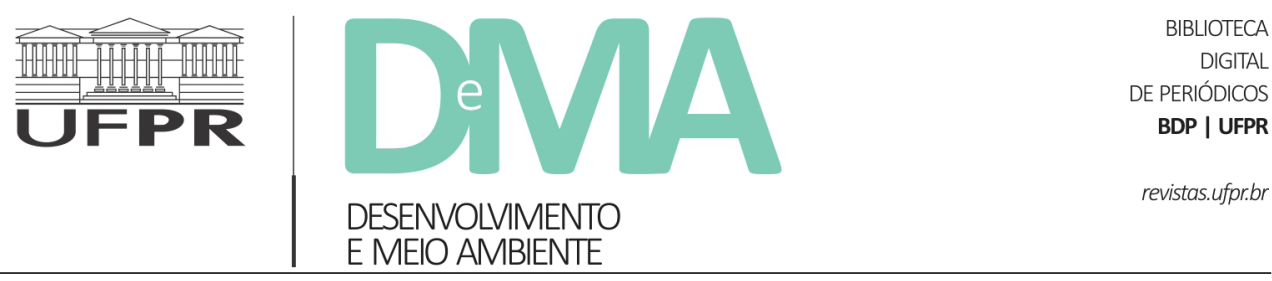

\title{
A expansão do agronegócio: impactos nefastos do desmatamento, agrotóxicos e transgênicos nas abelhas
}

\section{The expansion of agribusiness: harmful impacts of deforestation, pesticides and transgenics on bees}

\author{
Marcia Regina FAITA ${ }^{1 *}$, Adriana CHAVES ${ }^{1}$, Rubens Onofre NODARI ${ }^{1}$ \\ ${ }^{1}$ Programa de Pós-graduação em Recursos Genéticos Vegetais, Universidade Federal de Santa Catarina (UFSC), Florianópolis, SC, Brasil. \\ *E-mail de contato: marcia.faita@gmail.com
}

Artigo recebido em 30 de agosto de 2020, versão final aceita em 26 de fevereiro de 2021, publicado em 30 de junho de 2021.

RESUMO: O reconhecimento sobre os benefícios que as abelhas oferecem para a manutenção da vida não está sendo revertido em ações efetivas para conservação desses polinizadores. Nesse sentido, o objetivo deste artigo é apresentar e discutir os impactos de três importantes características do sistema agrícola industrial, que vem causando danos às abelhas no Brasil: desmatamento, uso de agrotóxicos e cultivo em larga escala de variedades transgênicas. Os danos agudos têm sido frequentemente relatados, tanto em estudos científicos quanto pela imprensa, diante de eventos de mortalidade em massa. Igualmente relevante, os danos crônicos informam sobre enfraquecimento e mortalidade de colmeias, sem apresentar uma causa única ou conclusiva. Estudos têm evidenciado que herbicidas, fungicidas e plantas transgênicas, mesmo considerados inócuos às abelhas, promovem alterações fisiológicas e comportamentais nesses insetos. Porém grande parte deles não indicam os reais prejuízos às colmeias, que só podem ser observados em estudos de longo prazo, realizados a campo. Isso também revela uma falha grave nas avaliações de riscos de agrotóxicos e transgênicos sobre organismos não alvo, que consideram válidos testes feitos em indivíduos isolados de organismos que naturalmente vivem em colônias, como é o caso das abelhas eussociais. Resultados obtidos para um grupo de indivíduos em laboratório, que não necessariamente refletem o efeito na colmeia, são muito comuns. Contudo, resultados de ensaios que consideram a complexidade de interações entre castas e diferentes gerações desses insetos, são muito escassos. Assim constata-se que o princípio da precaução foi sumariamente ignorado em detrimento aos lucros financeiros que se concentram para poucos, enquanto os prejuízos ambientais e à saúde são repartidos entre todos. Desse modo, apresentamos e discutimos os efeitos danosos de três das principais práticas utilizadas no âmbito do agronegócio brasileiro, que afetam de diferentes modos a saúde e sobrevivência das abelhas, assim como os serviços por elas prestados. 
Palavras-chave: fungicidas; herbicidas; simplificação da paisagem; monocultivos; danos crônicos e agudos.

ABSTRACT: The benefits that bees offer the ecosystem are increasingly recognized, but not met by actions designed to conserve these pollinators. Therefore, the present work aims to describe the impact of three key characteristics of agroindustry that are currently damaging bees in Brazil: deforestation, use of pesticides and large-scale cultivation of genetically modified (GM) varieties. We hear of mass mortality and weakening and damage to hives, but no conclusive causes are announced. In particular, studies indicate that fungicides, herbicides and GM plants, even when considered harmless to bees, still promote physiological and behavioral changes in these insects. However, most of these studies do not indicate the real damage to the hives, which can only be observed in long-term studies carried out in the field. Even when risk assessments of fungicides and herbicides are conducted in the field on non-targeted organisms, the tests are considered valid for isolated individuals without regard to the eusocial behavior of bees in their colonies. Some studies present results from experiments performed on individuals in the lab, again not necessarily reflecting hive activity. Results of trials that consider the complexity of interactions among castes and different generations of bees are very scarce. Therefore, we herein take a comprehensive and detailed approach to three practices of Brazilian agribusiness that directly affect bee and colony health and survival, as well as their ecoservices.

Keywords: fungicides; herbicides; monoculture; landscape simplification; chronic and acute damages

\section{Introdução}

Uma das principais preocupações relacionadas ao agronegócio é a crescente diminuição dos polinizadores, que é atribuído à expansão agrícola, ao desmatamento, uso de agrotóxicos e cultivo de plantas geneticamente modificadas. A intensificação da produção agrícola, ocorrida nas últimas décadas com grandes áreas de monoculturas e com o aumento do uso de agrotóxicos, promoveu a simplificação e fragmentação de paisagens (Freitas et al., 2009; Mullin et al., 2010; Cunha et al., 2014). Esses autores advertem de que esse cenário vem impactando as populações de inúmeras espécies de polinizadores em escala global, acarretando grandes prejuízos econômicos e ambientais.

Grande parte dos agrotóxicos utilizados não são seletivos, como é o caso dos inseticidas neonicotinóides, associados com a redução das populações de insetos polinizadores em diferentes países (Henry et al., 2012; Whitehorn et al., 2012;
Di Prisco et al., 2013; Godfray et al., 2014; Woodcock et al., 2017), tendo seu uso restringido pela União Europeia em 2013 (Carneiro et al., 2015). Além dos inseticidas, existem outros produtos que causam prejuízos às abelhas, consideradas os principais polinizadores. É o caso de herbicidas e fungicidas, que são pouco estudados quanto seus efeitos sobre as abelhas, uma vez que elas não são alvo desses agrotóxicos, não significando que não sejam prejudicadas de algum modo. Produtos denominados ingredientes inertes, que são substâncias misturadas aos ingredientes ativos nas formulações comerciais de agrotóxicos, também podem ter efeitos tóxicos sobre abelhas, comprometendo a saúde de suas populações (Zhu et al., 2014; Mullin et al., 2016).

Mesmo assim, foi difundida no país, com base nas recomendações técnicas de instituições públicas e privadas de pesquisa e extensão agrícola, chanceladas pelas políticas públicas e pelas agências encarregadas da aplicação da lei de agrotóxicos (Lei 
$\mathrm{n}^{\circ} 7.802$, de 11 de junho de 1989), a premissa de que é necessário utilizar agrotóxicos para garantir a produção de alimentos. Além disso, estabelece que os agrotóxicos, se utilizados de acordo com as recomendações dos fabricantes, não oferecem riscos a organismos não alvo e ao ambiente. Os resultados de parte de estudos científicos e de casos notificados por agências de regulação e fiscalização de agrotóxicos, apresentados no presente artigo, demonstram o contrário da referida premissa.

Nesse contexto, o objetivo do presente estudo é apresentar e discutir os efeitos danosos de três das principais práticas utilizadas no âmbito do agronegócio brasileiro, que são a simplificação da paisagem, o uso intensivo e frequente de fungicidas e herbicidas e o cultivo em larga escala de variedades geneticamente modificadas ou transgênicas sobre as abelhas. Desse modo, realizamos uma revisão de estudos científicos nacionais e internacionais, disponíveis em plataformas online (Scielo, Portal da CAPES e Google Acadêmico) que apresentassem informações relacionando herbicidas, fungicidas e variedades transgênicas com abelhas. Os artigos encontrados subsidiaram a construção deste documento.

Por que estudar efeitos de agrotóxicos que não são inseticidas, considerando que a abelha é um inseto? A razão é que os efeitos de um agrotóxico não se restringem ao organismo alvo, como sugere a classificação: inseticidas em insetos, fungicidas em fungos e bactérias, acaricidas em ácaros, herbicidas em plantas, e assim por diante. Em termos de toxicidade e danos aos seres vivos, os agrotóxicos oferecem riscos que independem da tipificação estabelecida pela sua natureza química, na qual se baseia a classificação legal. Exemplificando, existem evidências científicas de que, em termos de ação danosa aos seres vivos, um herbicida não causa danos só em plantas, mas pode causar também em abelhas (Faita et al., 2018; 2020; Chaves et al., 2020). Por isso, a classificação dos agrotóxicos atualmente em uso não permite prever quais danos os indivíduos de diferentes espécies sofrerão se expostos às formulações comerciais, compostas de ingredientes ativos e inertes, que desconsideram os efeitos a organismos não alvo.

\section{Polinizadores: importância das abelhas}

Tanto para a comunidade científica quanto para o restante da população, é incontestável a importância das abelhas para a polinização de espécies nativas e cultivadas que contribuem para o equilíbrio de ecossistemas naturais e para a produção de alimento (Potts et al., 2010). A obtenção dos produtos apícolas, embora sejam de extrema importância para a indústria de cosméticos, alimentícia e farmacêutica, é diminuta diante da relevância do serviço ambiental que é a polinização, gerando lucros diretos e indiretos (Faita, 2018). Dentre os insetos, as abelhas ocupam um lugar de destaque em serviços de polinização, sendo consideradas os polinizadores mais importantes (Malerbo-Souza \& Halak, 2009).

As abelhas dependem exclusivamente dos recursos florais para sua alimentação e sobrevivência, desenvolvendo uma relação de adaptações recíprocas com angiospermas (Pinheiro et al., 2014). A maioria delas, em especial as arbóreas, depende de polinizadores para completar o seu ciclo reprodutivo sexuado, produzindo sementes e frutos (Vieira \& Fonseca, 2014). 
A importância econômica dos polinizadores tem sido reconhecida na agricultura mundial. A Apis mellifera é considerada a principal abelha polinizadora, pois os serviços de polinização prestados por ela resultam em aumento de produtividade e qualidade de produtos de muitos cultivos (Roubik, 2002; Nascimento et al., 2012; Toledo et al., 2013). Adicionalmente, as espécies de abelhas nativas podem contribuir com o aumento da produtividade das plantas cultivadas (Heard, 1999; Bukovinszky et al., 2017), sendo responsáveis, conforme o ecossistema, por $40 \%$ a $90 \%$ da polinização das espécies vegetais (Heard, 1999). Uma vasta lista de plantas cultivadas depende totalmente desses animais ou se beneficiam com suas visitas. A ausência desse serviço pode afetar negativamente a reprodução sexuada e a diversidade genética das plantas, além de comprometer a produção de alimentos e produtos relacionados (Klein et al., 2007).

De acordo com Gallai et al. (2009), o valor econômico mundial do serviço de polinização por insetos, principalmente abelhas, foi de 153 bilhões de euros em 2005 para os principais cultivos que alimentam o mundo, correspondendo a 9,5\% do valor total da produção agrícola (Potts et al., 2010). Nos Estados Unidos, o valor estimado da polinização para a agricultura, apenas pelas abelhas $A$. mellifera, foi de 9,3 bilhões de dólares em 1989 e 14,6 bilhões em 2000, ou seja, um aumento de $36 \%$ (Morse \& Calderone, 2000).

Estudos realizados por Chiari et al. (2008), com o objetivo de verificar a influência da $A$. mellifera na produção de grãos e qualidade de sementes da soja transgênica Glycine max (L.) Merrill Roundup $^{\circledR}$ Ready e convencional, concluíram que, para as cultivares estudadas, houve benefício na produção de grãos de $37,84 \%$, quando foi permitida a visita de abelhas. No cultivo de laranjas, Malerbo-Souza \& Halak (2009) relataram a importância da entomofilia na produção desses frutos, pois vários experimentos de polinização em Citrus sp. comprovaram os benefícios na produção, quando as abelhas estão presentes, com aumento na frutificação das flores (Malerbo-Souza et al., 2003). Ainda nos cultivos de laranja, a produção de frutos maiores, mais doces e com maior quantidade de vitamina $\mathrm{C}$ ocorre na presença de abelhas, quando comparado ao tratamento sem abelhas (Gamito \& Malerbo-Souza, 2006).

Para estimar a contribuição econômica da polinização, Giannini et al. (2015b) realizaram um trabalho de revisão utilizando dados derivados de três fontes: (Klein et al., 2007), somente de espécies cultivadas no Brasil (Giannini et al., 2015a) e dados disponíveis na página eletrônica do Instituto Brasileiro de Geografia e Estatística (IBGE). De acordo com esses autores, a contribuição econômica dos polinizadores no Brasil totaliza quase $30 \%$ (aproximadamente 12 bilhões de dólares) do valor total da produção agrícola anual dos cultivos dependentes de polinização (aproximadamente 45 bilhões de dólares). Os autores utilizaram dados referentes aos anos de 2005 a 2012, incluindo todas as plantas de importância econômica, utilizadas como alimento, vestuário, gado, biocombustível ou para outro uso. Foi revisada a dependência das plantas por polinizadores e estimado o valor econômico anual da polinização para cada cultivo. Foram analisados 141 cultivos, dos quais 85 dependem de polinizadores. Quase um terço desses cultivos apresentou uma dependência grande ou essencial por polinizadores. Contudo não foram obtidas informações sobre a dependência de polinizadores para alguns cultivos importantes, o que mostra a necessidade urgente 
por pesquisa básica sobre biologia reprodutiva e ecologia da polinização (Giannini et al., 2015a).

Adicionalmente, é importante refletir sobre o panorama atual do estado de conservação ambiental, que interfere diretamente na manutenção da comunidade de polinizadores e seus serviços. Em um cenário otimista, a perda de serviços de polinização, para 29 dos principais cultivos relacionados à produção de alimento no Brasil, reduziria em 16,55 milhões de toneladas produzidas, correspondentes a 4,86 bilhões de dólares por ano. Já em uma previsão pessimista, esses mesmos valores seriam reduzidos para 51 milhões de toneladas e 14,56 bilhões de dólares por ano. Desse modo, afetaria o produto interno bruto (PIB) do país, reduzindo a contribuição agrícola em 6,46\% e 19,36\%, em cenários otimistas e pessimistas, respectivamente (Novais et al., 2016). Os autores alertaram ainda que o Brasil está vulnerável a uma crise de polinizadores, pois sua economia é de base profunda na agricultura e sua produção depende amplamente de polinizadores.

\section{Simplificação da paisagem: consequências do desmatamento e monocultura sobre as abelhas}

Em 28 de agosto de 2020, o MapBiomas divulgou a estimativa da perda de área de vegetação nativa, entre 1985 e 2019 , que equivale a 10,25\% do território nacional. A redução acumulada é de 87,2 milhões de hectares, conforme mostra a Coleção 5 do MapBiomas (MapBiomas, 2020). O mesmo trabalho mostrou ainda que mais da metade da perda de vegetação nativa no Brasil (44 milhões de hectares) ocorreu na Amazônia.
A ação antrópica sobre paisagens naturais, com desmatamento de florestas nativas, causa alterações no conjunto de componentes necessários à sobrevivência de vários organismos, em particular de abelhas, tanto solitárias quanto sociais. Durante a retirada da vegetação para implantação de atividades econômicas de interesse, colônias de abelhas são eliminadas juntamente com as árvores que as abrigam, contribuindo para a redução desses insetos (Santos, 2015). A expansão da agricultura, baseada nos princípios e práticas oriundos da Revolução Verde, provocou consequências drásticas em diferentes ecossistemas brasileiros. Desde sua origem na década de 1970, promoveu desmatamento em grandes áreas, crescendo a uma velocidade impressionante (Mesquita, 2009). Mesmo com os efeitos já conhecidos, o desmatamento ainda continua ocorrendo.

Episódios de intoxicação aguda, envolvendo a elevada mortalidade de abelhas, têm sido constatados com frequência por agências de fiscalização e noticiadas pela imprensa. A divulgação da morte de "ao menos 500 milhões de abelhas melíferas entre outubro de 2018 e março de 2019 em decorrência de agrotóxicos" é um exemplo desse tipo de episódio (Serb, 2019). Na divulgação dessa mesma notícia, o jornal informou que o laudo técnico do Laboratório Nacional Agropecuário do Rio Grande do Sul (Lanagro-RS), do Ministério da Agricultura, Pecuária a Abastecimento (MAPA), encontrou cinco tipos de agrotóxicos nas abelhas mortas, no mel, nas crias e nos favos. No Norte do país, já estão acontecendo fatos similares, em decorrência do cultivo da soja. O relato de 2019 indicou como a meliponicultura e a apicultura enfrentam um grave problema: o envenenamento de abelhas por agrotóxicos (Amazônia Latitude, 2019). O uso de agrotóxicos, incluído herbicidas, nas proximidades de meliponários, vem 
aumentando por causa da expansão do agronegócio na região de Belterra-PA, em particular do cultivo de soja transgênica.

A transformação de ambientes naturais para áreas agrícolas e/ou urbanas pode favorecer o isolamento de populações e colônias de abelhas devido à perda de habitat (Pinheiro-Machado et al., 2002). As mudanças no uso da terra reduzem áreas de nidificação e a disponibilidade de recursos florais (Ferreira et al., 2015; Kennedy et al., 2013), podendo comprometer a persistência de determinados táxons (Pinheiro-Machado et al., 2002). A fragmentação e descontinuidade das florestas impedem o fluxo gênico necessário à sobrevivência das colônias (Zayed, 2009). O isolamento de espécies que ocorre nessas situações acaba causando endogamia, contribuindo de forma significativa para a manifestação de genes recessivos, produzindo colônias fracas que morrem gradualmente pela eliminação da rainha (Caires \& Barcelos, 2017). Adicionalmente, o Brasil possui a maior diversidade de espécies de abelhas sociais sem ferrão do mundo, abrigando 300 das cerca de 400 espécies conhecidas (Michener, 2007). O que sabemos até agora sobre a biologia dessas abelhas é insuficiente para determinar ou identificar a sensibilidade ou vulnerabilidade delas a qualquer tipo de atividade humana (Pinheiro-Machado et al., 2002).

A intensificação agrícola também resulta na simplificação da paisagem, ameaçando o fornecimento de serviços ecossistêmicos essenciais, como a polinização (Connelly et al., 2015). Atividades como a pecuária, o extrativismo e o crescimento urbano exagerado também tem elevada relevância nesse processo, impulsionando o desmatamento e a simplificação dos habitats (Fearnside, 2005). A contínua substituição da vegetação natural, por plantação de lavouras e pastagens, prejudica ainda mais os polinizadores, pois carecem de diversidade floral e limitam o fornecimento de nutrientes às abelhas ao longo das estações (Blaauw \& Isaacs, 2014).

A agricultura com práticas de desmatamento, seguido de monocultivos, reduzem a diversidade de plantas nativas que são fontes de recursos tróficos às abelhas (Freitas et al., 2009). A riqueza e diversidade de espécies de polinizadores existentes no Brasil são afetadas pela expansão de áreas de monocultivos de espécies de importância econômica, como a soja, limitando as abelhas a uma dieta monofloral. Com o uso intensivo de agrotóxicos aplicados durante o ciclo de cultivo de soja, milho e algodão, populações de plantas espontâneas também são eliminadas. Se de um lado o desmatamento reduz o habitat para as abelhas, o monocultivo na sequência, conduzido em um sistema agrícola industrial ou químico, reduz a diversidade do pasto apícola na maior parte da área das grandes propriedades. Assim, restam os fragmentos florestais e as pequenas propriedades, quando são cultivadas várias variedades de espécies, como fonte de alimentos às abelhas.

Durante o forrageamento, as abelhas coletam néctar, pólen e/ou óleos como fonte de carboidrato e proteínas para todos os indivíduos do ninho (Faita, 2020). Abelhas que apresentarem modo de vida social usam comportamentos coletivos para combater as doenças em nível de colônia em um sistema denominado "imunidade social" (Cremer et al., 2007). Desse modo, cada abelha é capaz de se comunicar e responder às condições da colmeia, fazendo escolhas individuais que afetam a colônia, de modo que ela funcione de forma coletiva, como um superorganismo (Moritz \& Fuchs, 1998). Colmeias expostas a estressores que afetam sua capacidade de manter ou restaurar a imunidade social podem ficar muito fracas e morrer (Archer et al., 2014). 
Dentre outros fatores, pode-se destacar a desnutrição e a escassez de alimentos como eventos estressores que reduzem a imunidade das abelhas (Negri et al., 2019; Zaluski et al., 2020). Assim, abelhas que forrageiam áreas de monocultura têm uma dieta pouco diversificada, podendo não obter todos os nutrientes necessários (Brodschneider \& Crailsheim, 2010). Uma boa nutrição depende da diversidade de recursos florais presentes na alimentação desses insetos (Negri et al., 2019), do mesmo modo que a ausência dessas condições pode ocasionar a redução populacional da colmeia, comprometer o equilíbrio fisiológico e a resistência ao estresse das abelhas, aumentando sua vulnerabilidade a doenças e agrotóxicos (Archer et al., 2014).

Além de proteína e açúcares, as abelhas encontram, no pólen e no néctar, fitoquímicos que precisam para garantir suas necessidades individuais ou coletivas (Negri et al., 2019). Desse modo, as abelhas desenvolveram a capacidade de identificar as plantas que fornecem os fitoquímicos que precisam, passando a forragear em um sistema de "automedicação". O armazenamento de alimentos nas colmeias permite ainda que elas consigam ter acesso aos fitoquímicos mesmo quando as plantas fornecedoras não estejam em floração (Erler \& Moritz, 2016). A partir dessas informações, compreende-se que a sanidade das colmeias depende fundamentalmente da sua nutrição. Isso pode ser assegurado pela existência de locais com ambientes naturais preservados e ambientes agrícolas livres de agrotóxicos (Faita, 2020).

Com a simplificação das paisagens, outro serviço ecossistêmico negativamente afetado é o controle natural de pragas por inimigos naturais em plantações agrícolas. Os monocultivos, no geral, ge- ram desequilíbrio ecológico, pois ampliam a oferta de alimento para pragas, fazendo com que ocorra uma reprodução acelerada desses insetos nesses ambientes perturbados, com consequente maior uso de inseticidas. Portanto essa simplificação de paisagens, com pressão de pragas, também aumenta os custos de produção. Em estudo realizado em 2007 na região Centro-Oeste dos Estados Unidos, o custo no combate a pragas foi estimado em 69 milhões de dólares nos cultivos de soja, milho e trigo (Meehan et al., 2011). Os autores relataram que, além de contribuir para a redução de inimigos naturais e aumento de insetos-praga, as simplificações de paisagens foram associadas a menores rendimentos dos cultivos.

\section{Utilização de agrotóxicos no Brasil e os efeitos sobre as abelhas}

Os agrotóxicos são constituídos de múltiplas classes e subclasses de componentes e são comumente classificados quanto ao organismo alvo (herbicidas, inseticidas, fungicidas) ou de acordo com sua classe química (organofosforados, triazina, entre outras) (Bhalli et al., 2006). Desde 2008, o Brasil é o maior consumidor de agrotóxicos do mundo (Carneiro et al., 2015), apresentando um consumo superior a 300 mil toneladas por ano de produtos formulados, o que representa mais de 130 mil toneladas de ingredientes ativos consumidos anualmente. Importante estímulo ao consumo advém da diminuição dos preços e da grande isenção de impostos dos agrotóxicos, fazendo com que os agricultores utilizem maior quantidade por hectare (Pignati et al., 2011). 
No período entre 2000 e 2010, as vendas de agrotóxicos cresceram 190\%, enquanto a área plantada teve um aumento de $30 \%$. Esses dados demonstram a intensificação do uso desses produtos, aumentando seu consumo por hectare plantado, de acordo com dados da Agência Nacional de Vigilância Sanitária (ANVISA, 2011). O aumento no consumo médio de agrotóxicos em relação à área plantada passou de 10,5 litros por hectare, em 2002, para 12 litros por hectare em 2011 (Pignati et al., 2011). Esse número deve-se, em parte, às práticas de monocultura de cultivares transgênicos, ao desenvolvimento de resistência de plantas espontâneas, fungos e insetos e à mecanização agrícola (Gupta, 2004, 2007; Franco et al., 2010). Além disso, o clima tropical predominante no Brasil, juntamente com as mudanças climáticas, favorece a proliferação de doenças e pragas (Ghini et al., 2011), podendo contribuir para o alto consumo de insumos agrícolas. Contudo isso não diminui os problemas que esses produtos causam ao ambiente e organismos não alvo.

No Brasil, as plantações baseadas em monocultivos (ambientes simplificados) foram as que mais gastaram com agrotóxicos em 2006, principalmente os de soja e cana-de-açúcar (Porto \& Soares, 2012). Em 2015, os monocultivos de soja, milho e cana-de-açúcar equivaleram, juntos, a 76\% da área plantada no território brasileiro, respondendo por $82 \%$ do total de agrotóxicos utilizados no país. A soja foi a cultura que mais utilizou agrotóxicos, representando $63 \%$ do total, seguido do milho (13\%) e cana-de-açúcar (5\%) (Pignati et al., 2017). Portanto fica evidente que os produtos advindos do agronegócio, baseados em monocultivos extensivos, são os responsáveis pelo maior consumo de agrotóxicos na agricultura.
A comercialização e aplicação de agrotóxicos de forma intensiva e extensiva nos cultivos têm gerado discussões na maioria dos países quanto aos prejuízos que provocam, considerando o potencial citotóxico desses produtos sobre os organismos não alvos (Guillén et al., 2012). No Brasil, Pignati et al. (2017) avaliaram a correlação entre os indicadores de qualidade ambiental e de saúde humana para os municípios onde há maior consumo de agrotóxicos. Esses autores observaram que, conforme aumenta o consumo de agrotóxicos, cresce também o coeficiente médio da intoxicação aguda, subaguda (malformação fetal) e crônica (câncer infanto-juvenil).

Além disso, muitas outras pesquisas têm demonstrado os efeitos nocivos dos agrotóxicos em organismos não alvo, tais como os vertebrados. Entre eles, destacam-se as alterações no sistema respiratório e hepático (Santos Filho et al., 2003; Kesavachandran et al., 2006), e nas funções fisiológicas, como mudanças bioquímicas que desencadeiam estresse oxidativo e danos citogenéticos (Tope et al., 2006; Jia \& Misra, 2007). Os danos causados ao DNA, pelos agrotóxicos, podem desencadear processos carcinogênicos, anomalias morfológicas e alterações nos gametas, interferindo na fertilidade e na sobrevivência das populações (Bolognesi, 2003), além de gerar efeitos adversos crônicos na estrutura e dinâmica de populações e comunidades (Nacci et al., 1996; Kendall et al., 2001). A redução do tamanho populacional e a possível ocorrência da seleção de genótipos resistentes aos poluentes, por sua vez, atuam como efeito de gargalo genético e consequente perda de variabilidade (Theodorakis \& Shugart, 1998).

A avaliação dos riscos de um agrotóxico sobre determinado inseto deve inicialmente considerar a sua biologia. Insetos sociais apresentam divisão 
de trabalho entre os membros da colônia, com o desenvolvimento das atividades relacionados com a idade e fatores genéticos de cada indivíduo, deve-se considerar também a sua organização social (Calderone \& Page, 1992). O grupo dos Apiformes (Superfamília Apoidea) compreende sete famílias e mais de 16 mil espécies (Michener, 2007), com diferentes ciclos de vida, características comportamentais, morfológicas e fisiológicas entre si. Estudos que se propõem determinar o efeito de agrotóxicos sobre abelhas eussociais, em que os indivíduos são avaliados fora da colônia, não refletem a realidade. Nesse sentido, é preciso ter cautela ao definir o risco de um produto sobre organismos não alvo, especialmente às abelhas sociais.

As abelhas são consideradas bioindicadores de qualidade ambiental (Matin et al., 2016), pois em sua atividade de forrageio podem entrar em contato com diferentes contaminantes, sendo possível identificá-los nos produtos apícolas como mel e pólen (Silva \& Paz, 2012; de Oliveira Diniz et al., 2020). Além disso, as abelhas apresentam menor número de genes que codificam proteínas quando comparado com outros insetos, como é o caso da A. mellifera (Claudianos et al., 2006; Evans et al., 2006). As diferenças mais acentuadas ocorrem em três superfamílias que codificam enzimas de desintoxicação a xenobióticos, que podem representar maior sensibilidade das abelhas aos agrotóxicos (Claudianos et al., 2006). Essa característica inerente às abelhas revela a importância de estudos sobre os efeitos dos pesticidas nesses insetos, especialmente abordando a sinergia entre as combinações de xenobióticos, que representam interações que precisam ser consideradas nas avaliações de risco (Al-Waili et al., 2012).

O contato contínuo das abelhas com resíduos de agrotóxicos presentes no pólen e néctar de plantas cultivadas ou espontâneas promove a contaminação do mel (Sanchez-Bayo \& Goka, 2014). Essa contaminação também pode ocorrer a partir da substância presente na água consumida pelas abelhas para manter sua temperatura corporal e do enxame sob controle (Schmaranzer, 2000). Os resíduos presentes nesses meios podem estar abaixo da dose letal, porém persistem no mel, pólen e cera por períodos indeterminados, causando efeitos crônicos (Desneux et al., 2007; Goulson, 2013; Sánchez-Bayo \& Goka, 2014). Desse modo, é possível compreender que não só as abelhas forrageiras são contaminadas, mas também os demais indivíduos da colmeia estão em risco de exposição aos agrotóxicos (Prado et al., 2019). Como consequência, promovem alterações na capacidade cognitiva dos indivíduos, com grande impacto em sua geolocalização, prejudicando a coleta de alimento e comprometendo a manutenção da colônia (Sánchez-Bayo et al., 2016).

Em geral, as pesquisas que relatam os efeitos de agrotóxicos sobre abelhas concentram-se majoritariamente na abordagem dos efeitos de inseticidas, os quais afetam direta e efetivamente os insetos. No entanto há poucos estudos que abordam os efeitos de herbicidas e fungicidas, evidenciando a necessidade de pesquisas mais específicas e detalhadas nessa área, principalmente por exercerem efeitos subletais e, portanto, menos evidentes. No Brasil, o número de estudos desenvolvidos com o objetivo de identificar efeitos de herbicidas e fungicidas sobre abelhas ainda são escassos e, em sua maioria, são realizados com A. mellifera, que é uma espécie exótica. Contudo, exemplos de estudos sobre os efeitos adversos de herbicidas e fungicidas em abelhas feitos no Brasil estão listados na Tabela 1. 
TABELA 1 - Ingrediente ativo, modo de exposição, fase de vida dos insetos e efeito de herbicidas e fungicidas sobre abelhas das espécies nativas e exóticas de estudos desenvolvidos no Brasil.

\begin{tabular}{|c|c|c|c|c|c|c|}
\hline Classe & $\begin{array}{l}\text { Ingrediente } \\
\text { ativo }\end{array}$ & Espécie & $\begin{array}{l}\text { Modo de } \\
\text { contato }\end{array}$ & $\begin{array}{l}\text { Estágio de } \\
\text { vida }\end{array}$ & Efeito observado & Referência \\
\hline & Glifosato & $\begin{array}{l}\text { Apis melli- } \\
\text { fera }\end{array}$ & Oral & Adultas & $\begin{array}{l}\text { Redução na quantidade de geleia real produzida e enfraquecimen- } \\
\text { to de colmeias expostas ao herbicida, com população de abelhas } \\
\text { adultas, área de cria e estoque de alimento reduzido após } 130 \text { dias } \\
\text { da exposição. }\end{array}$ & Chaves et al. (2020) \\
\hline & Glifosato & $\begin{array}{l}\text { Apis melli- } \\
\text { fera }\end{array}$ & Oral & Adultas & $\begin{array}{l}\text { Aumento da mortalidade de abelhas contaminadas por Nosema } \\
\text { spp. }\end{array}$ & Faita et al. (2020) \\
\hline \multirow{3}{*}{ Herbicida } & $\begin{array}{l}\text { Glifosato e } \\
\text { 2,4-D }\end{array}$ & $\begin{array}{l}\text { Melipona } \\
\text { scutellaris }\end{array}$ & $\begin{array}{l}\text { Tópica e } \\
\text { oral }\end{array}$ & Adultas & $\begin{array}{l}\text { Em combinação, os herbicidas aumentaram a mortalidade; já na } \\
\text { exposição oral tanto à dose de campo recomendada como à dose } \\
\text { dupla, as abelhas reduziram a longevidade. }\end{array}$ & Nocelli et al. (2019) \\
\hline & Glifosato & $\begin{array}{l}\text { Apis melli- } \\
\text { fera }\end{array}$ & Oral & Adultas & $\begin{array}{l}\text { Alterações nas organelas celulares das glândulas hipofaríngeas, } \\
\text { promovendo a degeneração precoce dessas estruturas. }\end{array}$ & Faita et al. (2018) \\
\hline & Paraquat & $\begin{array}{l}\text { Apis melli- } \\
\text { fera }\end{array}$ & Oral & Adultas & $\begin{array}{l}\text { Aumento da mortalidade e expressão de genes de desintoxicação } \\
\text { em abelhas com dieta sem proteínas. }\end{array}$ & $\begin{array}{l}\text { de Mattos et al. } \\
\text { (2018) }\end{array}$ \\
\hline
\end{tabular}

$\begin{array}{ll} & \text { Tetragonisca } \\ \text { Paraquat } & \begin{array}{l}\text { angustula e } \\ \text { Nicosulfuron } \\ \text { Tetragonisca } \\ \text { fiebrigi }\end{array}\end{array} \quad$ Tópica Adultas Mudanças no padrão de expressão de isoenzimas.




\begin{tabular}{|c|c|c|c|c|c|c|}
\hline & $\begin{array}{l}\text { Piraclostro- } \\
\text { bina }\end{array}$ & $\begin{array}{l}\text { Apis melli- } \\
\text { fera }\end{array}$ & Oral & Adultas & Redução na expressão de proteínas da geleia real. & Zaluski et al. (2020) \\
\hline & $\begin{array}{l}\text { Picoxistro- } \\
\text { bina }\end{array}$ & $\begin{array}{l}\text { Apis melli- } \\
\text { fera }\end{array}$ & Oral & Adultas & $\begin{array}{l}\text { Alterações morfológicas e marcação positiva para morte celular } \\
\text { no intestino médio das abelhas, que pode ter suas funções de } \\
\text { absorção de nutrientes comprometidas. }\end{array}$ & Batista et al. (2020) \\
\hline & $\begin{array}{l}\text { Difenoco- } \\
\text { nazol }\end{array}$ & $\begin{array}{l}\text { Melipona } \\
\text { scutellaris }\end{array}$ & $\begin{array}{l}\text { Oral e } \\
\text { tópica }\end{array}$ & Adultas & $\begin{array}{l}\text { Causou mortalidade, assim como acúmulo desse produto nos } \\
\text { tecidos dos insetos. }\end{array}$ & Do Prado et al. (2020) \\
\hline & $\begin{array}{l}\text { Difenoco- } \\
\text { nazol }\end{array}$ & $\begin{array}{l}\text { Apis melli- } \\
\text { fera }\end{array}$ & Tópica & Adultas & $\begin{array}{l}\text { Baixa sobrevivência de abelhas expostas, com observação de } \\
\text { alterações comportamentais adversas, como agitação e mudanças } \\
\text { na coordenação motora. }\end{array}$ & Leite et al. (2018) \\
\hline & $\begin{array}{l}\text { Piraclostro- } \\
\text { bina }\end{array}$ & $\begin{array}{l}\text { Apis melli- } \\
\text { fera }\end{array}$ & Oral & Larvas & $\begin{array}{l}\text { O fungicida isolado não alterou a longevidade das larvas; no } \\
\text { entanto, em associação com o inseticida Clotianidina, reduziu a } \\
\text { longevidade das abelhas. }\end{array}$ & Tadei et al. $(2018$ \\
\hline \multirow[t]{4}{*}{ Fungicida } & $\begin{array}{l}\text { Piraclostro- } \\
\text { bina }\end{array}$ & $\begin{array}{l}\text { Apis melli- } \\
\text { fera }\end{array}$ & Oral & Adultas & $\begin{array}{l}\text { Alterações negativas sobre a morfologia das glândulas hipofarín- } \\
\text { geas. }\end{array}$ & Zaluski et al. (2017) \\
\hline & $\begin{array}{l}\text { Picoxistro- } \\
\text { bina }\end{array}$ & $\begin{array}{l}\text { Apis melli- } \\
\text { fera }\end{array}$ & Oral & Adultas & $\begin{array}{l}\text { Sobrevivência das colmeias foi reduzida e houve sobrecarrega- } \\
\text { mento do sistema hepatonefrocítico. }\end{array}$ & $\begin{array}{l}\text { Domingues et al. } \\
\text { (2017) }\end{array}$ \\
\hline & $\begin{array}{l}\text { Tiofanato- } \\
\text {-metílico e } \\
\text { clorotalonil }\end{array}$ & $\begin{array}{l}\text { Apis } \\
\text { mellifera e } \\
\text { Partamona } \\
\text { helleri }\end{array}$ & Oral & Adultas & $\begin{array}{l}\text { A mistura dos dois fungicidas causou toxidade com alta taxa de } \\
\text { mortalidade em ambas as espécies. }\end{array}$ & Tomé et al. (2017) \\
\hline & Captan & $\begin{array}{l}\text { Bombus } \\
\text { terrestris }\end{array}$ & Oral & Adultas & $\begin{array}{l}\text { Não houve efeitos significativos do tratamento sobre longevidade } \\
\text { da microcolônia, de trabalhador individual, consumo de pólen } \\
\text { ou xarope de açúcar, número de larvas descartadas, número de } \\
\text { zangões produzidos, ou tempo para a primeira oviposição.. }\end{array}$ & Malone et al. (2007) \\
\hline
\end{tabular}


Como é possível observar na Tabela 1, grande parte dos trabalhos desenvolvidos no Brasil utilizam como modelo biológico a espécie exótica Apis mellifera. Esta é uma abelha de grande importância econômica, manejada para produção de produtos apícolas e polinização dirigida (Souza et al., 2007). Contudo, em nosso país, são registradas cerca de 1700 espécies de abelhas nativas; destas, aproximadamente 300 pertencem à tribo Meliponini (Moure et al., 2007), apresentando comportamento eussocial, sobre as quais se tem poucas informações quanto aos efeitos de herbicidas e fungicidas.

As variações na sensibilidade entre espécies de abelhas a agrotóxicos foram avaliadas em diferentes estudos e apresentadas em uma metaanálise por Arena \& Sgolastra (2014). Com base em 150 estudos revisados pelos autores mencionados, as abelhas não Apis são menos tolerantes aos agrotóxicos do que abelhas Apis. Desse modo, fica evidente que não é possível fazer afirmações seguras sobre efeitos dos agrotóxicos em espécies de abelhas nativas brasileiras, utilizando como base estudos realizados com uma espécie exótica.

É necessário destacar que muitas espécies de abelhas nativas solitárias e sociais nidificam no subsolo e/ou utilizam lama para construir seus ninhos, estando mais expostas à agrotóxicos presentes nessa matriz. Também estão mais expostas durante o período larval, pois, diferente das abelhas melíferas que recebem geleia real e néctar, abelhas nativas são alimentadas com pólen não processado, onde há maior quantidade de resíduos de agrotóxicos quando comparado com néctar (Thompson et al., 2014) e outros produtos da colmeia (Calatayud-Vernich et al., 2018). Além disso, quando nidificam naturalmente, não podem ser movidas temporariamente durante pulverizações de agrotóxicos e, no caso de abelhas solitárias, a morte de uma fêmea em nidificação resulta no fim da atividade reprodutiva daquela espécie (Arena \& Sgolastra, 2014). Nesse sentido, fica evidente que o aumento da simplificação da paisagem, substituição da vegetação nativa por cultivo de variedades transgênicas e, consequentemente, maior aplicação de agrotóxicos, em conjunto, configuram reais ameaças a diferentes espécies de abelhas. Ações que contribuam para a mitigação dos prejuízos sobre abelhas são urgentes e necessárias.

\section{Exemplos de danos diretos do cultivo de variedades transgênicas de plantas nas abelhas}

Desde 1973, com o advento da Tecnologia de DNA Recombinante, posteriormente denominada de engenharia genética, foram apresentadas as cautelas necessárias ao desenvolvimento e uso dos produtos da tecnologia. Um desses produtos são as variedades transgênicas ou geneticamente modificadas (GM), cujos genes produzem novos produtos e alteram a regulação gênica da variedade hospedeira dos genes recombinantes ou transgenes. É relevante destacar que os possíveis riscos ecológicos foram antecipados, ainda em 1989, portanto cinco anos antes da liberação comercial da primeira variedade transgênica (Tiedje et al., 1989). Dentre os possíveis riscos relacionados às abelhas estavam: (i) a produção de substâncias que são ou poderiam ser tóxicas a organismos não alvos; (ii) o efeito disruptivo em comunidades bióticas e o desperdício de valiosos recursos genéticos, seguido de contaminação de espécies nativas, com características originadas de parentes distantes ou de espécies não relacionadas, 
e efeitos adversos em processos dos ecossistemas; (iii) a origem de substâncias secundárias tóxicas após a degradação incompleta de químicos perigosos; e (iv) os efeitos adversos nos processos ecológicos. Todos esses riscos se transformaram em danos reais para as abelhas, parte dos quais são exemplificados no presente artigo (Tabela 2).

Embora não existam estatísticas oficiais no país, a empresa Céleres divulga a estimativa de área cultivada no Brasil com variedades transgênicas, que, na safra 2018/2019, teria alcançado cerca de 51,8 milhões de hectares. Nessa área, as variedades transgênicas de algodão, milho e soja com os genes recombinantes (provindos de Baccilus thuringiensis), que codificam para a produção de toxinas com função inseticida contra insetos, ocuparam 72\% da área cultivada na safra referida (Céleres, 2019). Simultaneamente aos primeiros alertas, já eram feitos estudos com as toxinas nativas de Baccilus thuringiensis $(B t)$ visando prever os possíveis impactos em abelhas das toxinas recombinantes que estavam sendo desenvolvidas. Assim, a taxa de mortalidade de abelhas, quando foram alimentadas com esporos de $B$. thuringiensis ou com a proteína Cry, foi maior do que naquelas não expostas às toxinas (Vandenberg \& Shimanuki, 1990; Vandenberg, 1990). Mais tarde, foram novamente comprovados efeitos deletérios das toxinas produzidas pelos genes cry, nativos ou recombinantes, nas atividades de forrageamento, comportamento alimentar e desempenho de aprendizagem, que podem ter um impacto no desenvolvimento da colmeia (Ramirez-Romero et al., 2005, 2008).

Em geral, estudos com abelhas sociais são realizados com indivíduos da casta de operárias, que, em condições naturais, apresentam sobrevivência média de 35 dias. Nesses casos, os bioensaios são conduzidos em laboratório sob condições artificiais de umidade, temperatura e luminosidade, com duração inferior ao período de sobrevivência das abelhas operárias (Tabela 2).

Além dos estudos com as proteínas isoladas, os efeitos do pólen contendo as toxinas Cry também comprovaram os efeitos adversos desse grupo de toxinas, que tem ação inseticida. $\mathrm{O}$ resultado das análises de abelhas diretamente em colmeias que se alimentaram de pólen de milho Bt, contendo o rcrylF (crylF recombinante) que codifica para a toxina Cry1F, revelou que houve aumento significativo da infestação do ácaro Varroa destructor em abelhas adultas, bem como redução do comportamento higiênico das colônias expostas à toxina Cry1F; comparativamente, as colmeias controle (Bizzocchi, 2014). Malone et al. (2007) verificaram que a toxina produzida pela proteína reduziu o tempo de sobrevivência de abelhas alimentadas com dieta contendo a proteína Cry $1 \mathrm{Ab}$.

Os resultados acima mencionados, e associados com o fato de que as abelhas não possuem capacidade de distinguir flores transgênicas de não transgênicas (Malone \& Pham-Dèlègue, 2001; Sabugosa-Madeira et al., 2007), permitem admitir que bioensaios em laboratório não correspondem ao risco de danos que as abelhas podem estar expostas em condições de campo. É possível que a proximidade e a escala do cultivo de variedades GM, produtoras de toxinas com função inseticida, causem mais prejuízos às abelhas do que é revelado pelos experimentos em laboratório, como é o caso daquelas portadoras de genes cry, vir e outros, isolados de $B$. thuringiensis e alterados geneticamente in vitro, que permitem maior eficiência e amplitude na ação tóxica. 
Para as abelhas, os efeitos indiretos do cultivo de variedades GM são também muito críticos. $\mathrm{O}$ pólen de organismos geneticamente modificados (OGM) é tóxico também para insetos que coabitam nas colmeias, tais como traças de cera Achroia grisella e Galeria mellonela (Hanley et al., 2003; Oldroyd, 2007; Trevisan et al., 2013). Esse resultado, combinado com o fato de que colônias mortas apresentando sintomas característicos de Desordem de Colapso da Colônia (DCC) não continham traças-da-cera vivas e o besouro da espécie Aethina tumida nos favos abandonados (Sabugosa-Madeira et al., 2007), indica danos causados indiretamente pela presença de pólen transgênico, expressando as toxinas inseticidas em colmeias.

Outro tipo de efeito indireto é proporcionado também pelo cultivo de variedades transgênicas resistentes a herbicidas. Nesse caso, o uso da variedade GM é associado ao uso de herbicidas que são aplicados sobre as plantas dessas variedades resistentes. No entanto, neste sistema de cultivo, o efeito indireto se constitui da diminuição da oferta de recursos apícolas às abelhas. Grupos de abelhas e borboletas foram afetados de forma semelhante pela aplicação de herbicidas em lavouras de variedades GM de beterraba, semeada na primavera, e canola, no inverno, causando um impacto negativo na abundância de polinizadores e, possivelmente, na polinização (Bohan et al., 2005). Assim, os autores do artigo sugeriram que, durante a estação de crescimento das plantas GM, a menor abundância de dicotiledôneas no sistema de cultivo com o uso de herbicidas sobre toda a área cultivada sugere que as abelhas, bem como outros animais que dependem de dicotiledôneas, não se sairiam bem se esse sistema de cultivo fosse amplamente adotado.
Essa ampla adoção de variedades GM resistentes a herbicidas - associados ao aumento do uso desses agrotóxicos - ocorreu no Brasil nos últimos 20 anos. Na Safra de 2018/2019, foram cultivados 34,7 milhões de hectares de soja, 15,6 milhões de hectares de milho e 1,44 milhões de hectares de algodão (Céleres, 2019). Nesse mesmo informe consta que, nas variedades das três espécies mencionadas, 7,5\% contém genes que produzem toxinas com função inseticidas, $27,6 \%$ contém genes de resistência a herbicidas e $64,5 \%$ contém ambas as características (Céleres, 2019). Além disso, duas variedades de soja têm genes que aumentam a tolerância à seca, mas a área cultivada não foi informada. Também foram aprovadas para cultivo: uma variedade de cana-de-açúcar, uma variedade de feijão e uma variedade de eucalipto - contendo, respectivamente, genes de produção de toxinas, resistência a um vírus e aumento volumétrico de madeira.

Desde antes da aprovação comercial das plantas transgênicas, cientistas e apicultores manifestaram suas preocupações dos possíveis efeitos do cultivo destas. A primeira preocupação está associa aos efeitos tóxicos diretos ou indiretos em abelhas. A segunda diz respeito à contaminação de variedades não transgênicas pelas variedades transgênicas, que poderia ser mediada pelo fluxo gênico com auxílio de abelhas. E isso tem ocorrido entre variedades de canola e de milho. Embora o pólen possa ser levado de uma lavoura para outra pelo vento, as abelhas são visitantes florais em variedades de milho (Figura 1) ou soja (Figura 2), convencionais ou transgênicas.

Além de contribuir para contaminar as lavouras de variedades crioulas de produção orgânica e agroecológica, o pólen de milho transgênico levado até as colmeias contamina o mel produzido. A detecção de pólen de milho transgênico no mel 
em amostras do México (Gálvez-Mariscal, 2013), assim como de soja transgênica no mel, ocorreu, entre outros, na Argentina (Gallez et al., 2005) e no México (Villanueva-Gutiérrez et al., 2014). Como a regulamentação brasileira (CTNBio, 2007) estabelece uma distância máxima de 100 metros entre lavouras de milho GM e de milho não GM, essa norma, mesmo que obedecida, não evita que abelhas ou o vento levem pólen de uma lavoura para outra. A conclusão é inequívoca: não há coexistência com as lavouras que cultivam variedades GM sem prejuízo para aos produtores de milho orgânico ou de mel de abelhas.

Como o pólen está presente no mel, mesmo que em quantidade mínima, ele foi considerado, na União Europeia, um ingrediente do mel e não um componente natural. Assim, pela decisão da European Court of Justice em 6 de setembro 2011 (Case C-442/09), o mel contaminado com pólen de organismos geneticamente modificados foi incluído

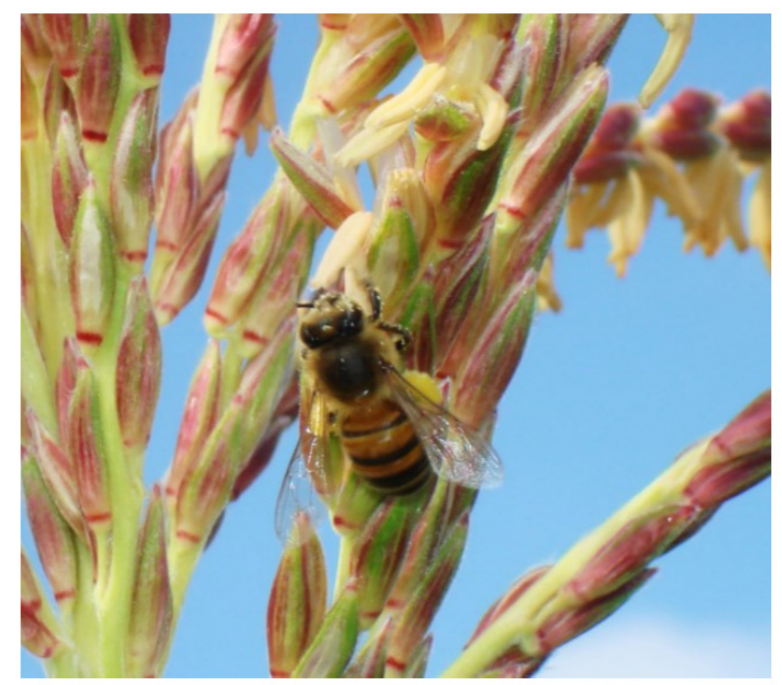

FIGURA 1 - Abelha coletando pólen de variedade de milho transgênica. FOTO: Acervo pessoal dos autores. na classificação de gêneros alimentícios que requerem autorização de introdução no mercado europeu (Lamping, 2012). Assim, sempre que uma abelha coleta pólen de uma planta geneticamente modificada, isso pode fazer com que toda colheita de mel seja não comercializável (Lamping, 2012), representando um dano socioeconômico aos apicultores.

Além da detecção de DNA ou proteína dos transgenes presentes em variedades GM, resíduos do herbicida à base de glifosato (HBG), associado às variedades $\mathrm{GM}$ resistentes a herbicidas, também têm sido detectados em mel. O estudo de Rubio et al. (2014), feito com méis adquiridos nos Estados Unidos, constatou que $45 \%$ das 11 amostras de mel orgânico e $62 \%$ das 58 amostras de mel não orgânico tinham resíduo de glifosato. De acordo com os autores, de um modo geral, os níveis de glifosato foram menores em amostras oriundas de países que não tinham autorizado o cultivo comercial de variedades GM.

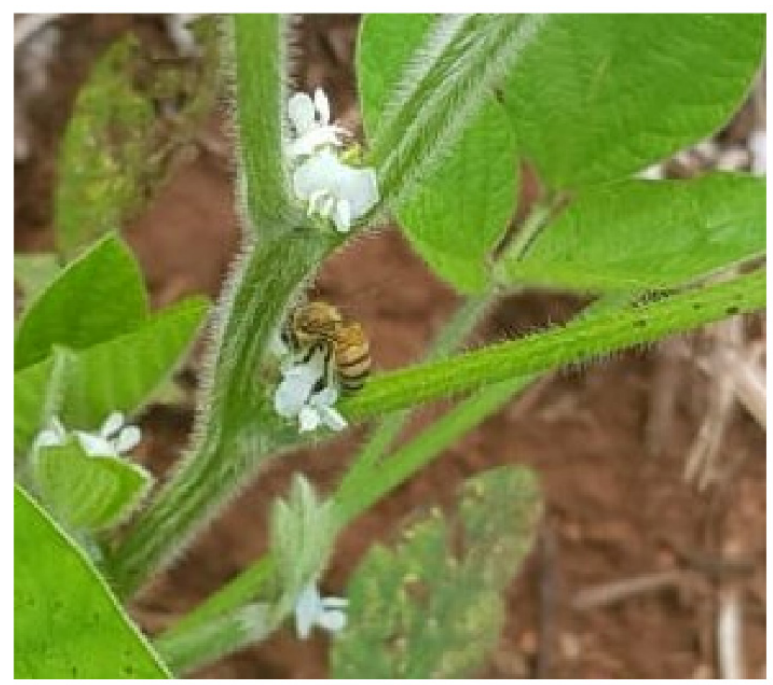

FIGURA 2 - Abelha coletando pólen de variedade de soja transgênica. FOTO: Prof. Márcio do Nascimento Ferreira. 
TABELA 2 - Toxina recombinante, modo de exposição, estágio de vida das abelhas e efeito da toxina expressada por plantas transgênicas sobre abelhas.

\begin{tabular}{|c|c|c|c|c|c|c|}
\hline Gene & Produto & Espécie & Modo de exposição & $\begin{array}{l}\text { Estágio de vida } \\
\text { e condução do } \\
\text { bioensaio }\end{array}$ & $\begin{array}{l}\text { Efeitos comparativamente ao tratamento } \\
\text { controle }\end{array}$ & Autor \\
\hline rbar & $\begin{array}{l}\text { Confere } \\
\text { resistência } \\
\text { ao herbicida } \\
\text { Glufosinato } \\
\text { de amônia em } \\
\text { plantas }\end{array}$ & Em geral & $\begin{array}{l}\text { Redução de alimento } \\
\text { (pólen/néctar) por } \\
\text { três anos }\end{array}$ & Adultos & $\begin{array}{l}\text { Redução da diversidade e abundância de } \\
\text { abelhas. }\end{array}$ & $\begin{array}{l}\text { Bohan et al. } \\
(2005)\end{array}$ \\
\hline$n c r y 1 A b$ & Toxina & $\begin{array}{l}\text { Apis } \\
\text { mellifera }\end{array}$ & $\begin{array}{l}\text { Ingestão de toxina no } \\
\text { xarope por } 10 \text { dias }\end{array}$ & $\begin{array}{l}\text { Larvas com } 2 \text { dias, } \\
\text { em gaiolas por } 15 \\
\text { dias }\end{array}$ & $\begin{array}{l}\text { Aumento do tempo para consumo de ali- } \\
\text { mento, xarope contaminado com a proteína } \\
\text { Cry } 1 \mathrm{Ab} \text {, similar ao tempo para consume do } \\
\text { xarope com imidacloprid, e desempenho de } \\
\text { aprendizagem perturbado. }\end{array}$ & $\begin{array}{l}\text { Ramirez- Ro- } \\
\text { mero et al. } \\
(2008)\end{array}$ \\
\hline $\operatorname{rcry} 1 A c+c p T I$ & $\begin{array}{l}\text { Toxina + Inibi- } \\
\text { dor de tripsina }\end{array}$ & $\begin{array}{l}\text { Apis } \\
\text { mellifera }\end{array}$ & $\begin{array}{l}\text { Ingestão de pólen } \\
\text { contendo toxina por } \\
\text { sete dias }\end{array}$ & $\begin{array}{l}\text { Larvas } \\
\text { Laboratório }\end{array}$ & $\begin{array}{l}\text { Aumento }(50 \%) \text { na taxa de mortalidade, } \\
\text { similar à causada por imidaclopride, e menor } \\
\text { consumo de pólen GM e que contém resíduo } \\
\text { de imidaclopride. }\end{array}$ & $\begin{array}{l}\text { Han et al. } \\
(2010)\end{array}$ \\
\hline crylAc & $\begin{array}{l}\text { Toxina purifi- } \\
\text { cada }\end{array}$ & $\begin{array}{l}\text { Apis melli- } \\
\text { fera }\end{array}$ & $\begin{array}{l}\text { Ingestão dieta con- } \\
\text { tendo Cry1Ac por } \\
\text { cinco dias }\end{array}$ & $\begin{array}{l}\text { Larvas }<24 \mathrm{~h} \text { até } 18 \\
\text { dias, em incubadora } \\
\text { com demanda bio- } \\
\text { química de oxigênio } \\
\text { (BOD). }\end{array}$ & $\begin{array}{l}\text { A adição de água à dieta a toxina Cry } 1 \mathrm{Ac} \\
\text { causou significativo aumento na mortalidade } \\
\text { larval, mas não afetou o tempo de desenvol- } \\
\text { vimento pupal. }\end{array}$ & $\begin{array}{l}\text { Lima et al. } \\
(2010)\end{array}$ \\
\hline rcrylAh & $\begin{array}{l}\text { Toxina expressa } \\
\text { em B. thurin- } \\
\text { giensis }\end{array}$ & $\begin{array}{l}\text { Apis melli- } \\
\text { fera e A. } \\
\text { cerana }\end{array}$ & $\begin{array}{l}\text { Ingestão de xarope } \\
\text { contendo rCry1Ah } \\
\text { por nove dias }\end{array}$ & $\begin{array}{l}\text { Larvas }<12 \mathrm{~h} \text {, Gaio- } \\
\text { las por } 21 \text { dias }\end{array}$ & $\begin{array}{l}\text { Não houve diferença na sobrevivência, } \\
\text { consumo de pólen e massa da glândula } \\
\text { hipofaríngea. }\end{array}$ & Dai et al. (2012) \\
\hline
\end{tabular}




\begin{tabular}{|c|c|c|c|c|c|c|}
\hline rcrylF & Toxina & $\begin{array}{l}\text { Apis melli- } \\
\text { fera }\end{array}$ & $\begin{array}{l}\text { Ingestão de pólen } \\
\text { contendo a toxina } \\
\text { por três semanas }\end{array}$ & $\begin{array}{l}\text { Larvas de } 10-14 \text { dias } \\
\text { em colmeias }\end{array}$ & $\begin{array}{l}\text { Redução do comportamento higiênico das } \\
\text { colônias e aumento da infestação do ácaro } V \text {. } \\
\text { destructor em abelhas adultas. }\end{array}$ & $\begin{array}{l}\text { Bizzocchi } \\
(2014)\end{array}$ \\
\hline crylF & Toxina & $\begin{array}{l}\text { Melipona } \\
\text { quadrifas- } \\
\text { ciata }\end{array}$ & $\begin{array}{l}\text { Ingestão de alimento } \\
\text { artificial contendo a } \\
\text { toxina }\end{array}$ & $\begin{array}{l}\text { Larvas; } \\
\text { Laboratório. }\end{array}$ & $\begin{array}{l}\text { Não afetou a taxa de sobrevivência, mas } \\
\text { diminuiu o período de alimentação. }\end{array}$ & $\begin{array}{l}\text { Seide et al. } \\
\text { (2018) }\end{array}$ \\
\hline rcry $2 A a$ & Toxina & $\begin{array}{l}\text { Melipona } \\
\text { quadrifas- } \\
\text { ciata }\end{array}$ & $\begin{array}{l}\text { Ingestão de alimento } \\
\text { artificial contendo a } \\
\text { toxina }\end{array}$ & $\begin{array}{l}\text { Larvas; } \\
\text { Laboratório. }\end{array}$ & $\begin{array}{l}\text { Aumento na taxa de sobrevivência, mas } \\
\text { atraso no desenvolvimento. }\end{array}$ & $\begin{array}{l}\text { Seide et al. } \\
\text { (2018) }\end{array}$ \\
\hline
\end{tabular}




\section{Considerações finais}

Os esforços da comunidade científica têm contribuído significativamente para elucidar as causas do fenômeno de mortalidade em massa das abelhas, observado em diferentes partes do mundo. Todas as descobertas apontam para um conjunto de fatores que incluem, entre outros, a simplificação da paisagem, o uso de agrotóxicos e o monocultivo em larga escala de plantas transgênicas. Em conjunto, essas três práticas promovem carência nutricional nas abelhas, debilitando seu sistema imunológico, deixando-as vulneráveis a parasitas e patógenos, além de reduzir os locais de nidificação.

As evidências sobre efeitos subletais de herbicidas e fungicidas indicam que os prejuízos em abelhas, desses produtos ditos inócuos pelos fabricantes, não devem ser ignorados. Além disso, grande parte dos estudos referem-se às abelhas da espécie A. mellifera, considerada o polinizador mais efetivo, além de grande produtora de mel e outros produtos apícolas. São mínimas, ainda, as informações sobre os efeitos de agrotóxicos nas espécies de abelhas sem ferrão do Brasil, cuja diversidade é a maior do mundo (Michener, 2007) e está sendo perdida antes mesmo de ser detalhadamente conhecida. $\mathrm{O}$ comprometimento de seus habitats naturais interfere diretamente na sua sanidade e sobrevivência.

É relevante mencionar que a classificação arbitrária dos agrotóxicos em inseticidas, fungicidas e herbicidas, entre outros, não reflete qual é de fato o organismo alvo de atuação de cada um dos produtos. Os exemplos mencionados neste artigo e um vasto conjunto de estudos vêm demonstrando que o alvo de um inseticida, ou fungicida, ou herbicida, compreende um grande conjunto de espécies, fora do escopo que a classificação sugere. Embora no presente estudo foram incluídos os efeitos comprovados de ingredientes ativos isoladamente, pólen contaminado com misturas de agrotóxicos pode diminuir a resistência de abelhas às doenças, como a nosemose por exemplo, o que foi constatado quando o pólen coletado pelas abelhas estava com resíduos de inseticidas e fungicidas (Pettis et al., 2013).

Adicionalmente, vivenciamos no Brasil, no presente momento, uma dinâmica de novas e constantes liberações de agrotóxicos proibidos em outros países (Hess et al., 2021 - nesse número especial), bem como a manutenção de incentivos fiscais no comércio desses produtos, enquanto faltam recursos para realizar pesquisas sobre os efeitos de longo prazo de agrotóxicos em organismos não alvo. Também somos forçados a conviver com limites de permissividade de resíduos que não são aceitáveis em outros países, gerando um cenário nefasto para as abelhas e demais seres vivos. Não, não é exagero. Há décadas recebemos sucessivos alertas sobre os riscos das ações humanas sobre a biosfera, que inicialmente foram tratados como exageros, mas que, ao longo do tempo, mostraram-se reais, quando estudos contextualizados foram realizados.

Diante do exposto neste artigo, para evitar a continuidade dos danos de agrotóxicos, transgênicos e desmatamento às abelhas e demais seres vivos, a precaução deveria ser um dos princípios a serem utilizados para guiar as atividades humanas. O princípio da precaução incorpora parte de outros conceitos como justiça, equidade, respeito, senso comum e prevenção. De acordo com o princípio da precaução, o ônus da prova da ausência de efeitos danosos de uma tecnologia caberia ao proponente da tecnologia. No entanto, além de não exigir as avaliações de riscos na profundidade requerida, as 
políticas públicas brasileiras isentam de impostos e de responsabilidade os danos provocados por agrotóxicos a quem realmente cabe, que são as empresas que os fabricam e comercializam como produtos inócuos nas doses recomendadas. Existem fragilidades tanto na legislação como na atuação das agências regulatórias e de fiscalização; contudo é inaceitável que a responsabilidade seja atribuída unicamente aos agricultores que fazem uso desses produtos.

Mas os agrotóxicos são um dos componentes do agronegócio. Do modo que está estabelecido, o modelo do agronegócio provoca danos irreversíveis ao ambiente, que afetam a saúde de todos os seres vivos e os processos ecológicos. Igualmente relevante é a destruição das florestas nativas e diversidade biológica. Enquanto grandes empresas lucram com a venda de agroquímicos e de sementes transgênicas, os contribuintes brasileiros arcam com o custo social e ambiental dos efeitos adversos desse sistema de cultivo.

O princípio da precaução relaciona-se, ainda, com a associação respeitosa e funcional do homem com a natureza, concretizada por sistemas agrícolas de baixo impacto, como a agroecologia e a produção orgânica. Esses sistemas não utilizam variedades transgênicas nem agrotóxicos e produzem alimentos de alta qualidade biológica. Os benefícios da agroecologia estão associados, entre outros aspectos, à ecologia, em razão da redução da poluição da água e do solo e da conservação da biodiversidade (Nodari \& Guerra, 2015). Estes e outros benefícios decorrem das práticas agroecológicas que contribuem ainda para a recuperação de bacias hidrográficas e reduzem a dependência de insumos externos. Por fim, os produtos agroecológicos promovem a saúde, pois possuem maior valor nutritivo e menos resíduos de agrotóxicos e metais pesados (Barański et al., 2014).

No atual cenário da agricultura, a pesquisa contextualizada contribui sobretudo de duas maneiras. Primeiramente, é capaz de transformar o estado de ignorância e incerteza em risco associado a um novo produto ou atividade. A importância de conhecer o risco reside no fato de que, daí em diante, eles podem ser evitados ou minimizados, por meio de estratégias e medidas de gestão de risco que contemplem ações antecipatórias para proteger a saúde das pessoas e dos ecossistemas. Contudo, sem conhecê-los, isto se torna impossível. A segunda, quando executada de forma participativa com os agricultores, a pesquisa contextualizada contribui com o avanço no conhecimento científico que embasa princípios e processos agroecológicos, que são apropriados e inovados pelos agricultores agroecológicos.

\section{Agradecimentos}

Os autores agradecem a Coordenação de Aperfeiçoamento de Pessoal de Nível Superior (CAPES) pelas bolsas concedidas a MRF and AC (Finance Code 001) e ao Conselho Nacional de Desenvolvimento Científico e Tecnológico (CNPq) pela Bolsa PQ a RON (Proc. 303902/2017-5).

\section{Referências}

Al-Waili, N.; Salom K.; Al-Ghamdi A, Ansari M.J. Antibiotic, Pesticide, and Microbial Contaminants of Honey: Human Health Hazards. The Scientific World Journal, 2012 (Table 1), 1-9, 2012. doi: 10.1100/2012/930849

Amazônia Latitude. Agronegócio em Belterra gera aumen- 
to na mortalidade de abelhas. Amazônia Latitude, 02 de maio de 2019. Disponível em: < https://amazonialatitude. com/2019/05/02/agronegocio-em-belterra-gera-aumento-mortandade-abelhas/\#: :text=O\%20meliponicultor $\% 20$ aponta $\% 20$ para $\% 20$ o,regula $\% \mathrm{C} 3 \% \mathrm{~A} 7 \% \mathrm{C} 3 \% \mathrm{~A} 30 \% 20$ do $\% 20$ plantio $\% 20$ de $\% 20$ soja.\&text $=\mathrm{Al} \% \mathrm{C} 3 \% \mathrm{~A} 9 \mathrm{~m} \% 20$ da\%20 contamina $\%$ C3\%A7\%C3\%A30\%20das $\% 20$ abelhas,na\%20temperatura $\% 20$ ambiente $\% 20$ na $\% 20$ regi $\%$ C3\%A3o>. Acesso em: mai. 2020.

ANVISA. Agência Nacional de Vigilância Sanitária. Sistemas de Informações sobre agrotóxicos. Disponível em: $<\mathrm{http}$ ://portal.anvisa.gov.br/agrotoxicos $>$. Acesso em: mai. 2020.

Archer, C. R.; Pirk, C. W. W.; Wright, G. A.; Nicolson, S. W. Nutrition affects survival in African honeybees exposed to interacting stressors. Functional Ecology, 28(4), 913-923, 2014. doi: $10.1111 / 1365-2435.12226$

Arena, M.; Sgolastra, F. A meta-analysis comparing the sensitivity of bees to pesticides. Ecotoxicology, 23 (3), 324-334, 2014. doi: 10.1007/s10646-014-1190-1

Barański, M.; Średnicka-Tober, D.; Volakakis, N.; et al. Higher antioxidant and lower cadmium concentrations and lower incidence of pesticide residues in organically grown crops: A systematic literature review and meta-analyses. Brazilian Journal of Nutrition, 112(5), 794-811, 2014. doi: 10.1017/S0007114514001366

Batista, A.C.; Domingues, C.E. da C.; Costa, M.J.; Silva-Zacarin, E.C.M. Is a strobilurin fungicide capable of inducing histopathological effects on the midgut and Malpighian tubules of honey bees? Journal of Apicultural Research, 59(5), 834-843, 2020. doi:10.1080/00218839.2020.1724678

Bhalli, J.A.; Khan, Q.M.; Haq, M.A.; Khalid, A.M.; Nasim, A. Cytogenetic analysis of Pakistani individuals occupationally exposed to pesticides in a pesticide production industry. Mutagenesis, 21(2), 143-148, 2006. doi: 10.1093/ mutage/gel009

Bizzocchi, L. Avaliação dos Impactos do Pólen de Milho Geneticamente Modificado (Bt) Sobre colônias de Apis mellifera L. Florianópolis, Dissertação (Mestrado em Ciências - Recursos Genéticos Vegetais) - UFSC, 2014.

Blaauw, B. R.; Isaacs, R. Flower plantings increase wild bee abundance and the pollination services provided to a pollination-dependent crop. Journal of Applied Ecology, 51(4), 890-898, 2014. doi: 10.1111/1365-2664.12257

Bohan, D.; Boffey, C.; Brooks, D.; Clark, S.; Dewar, A.; Firbank, L.; Haughton, A.; Hawes, C.; Heard, M.; May, M.; Osborne, J.; Perry, J.; Rothery, P.; Roy, D.; Scott, R.; Squire, G.; Woiwod, I.; Champion, G. Effects on weed and invertebrate abundance and diversity of herbicide management in genetically modified herbicide-tolerant winter-sown oilseed rape. Proceedings of the Royal Society B: Biological Sciences, 272(1562), 463-474. 2005. doi:10.1098/rspb.2004.3049

Bolognesi, C. Genotoxicity of pesticides: a review of human biomonitoring studies. Mutation Research/Reviews in Mutation Research, 543(3), 251-272, 2003. doi: 10.1016/ S1383-5742(03)00015-2

Brodschneider, R.; Crailsheim, K. Nutrition and health in honey bees. Apidologie, 41(3), 278-294, 2010. doi: 10.1051/ apido/2010012

Bukovinszky, T.; Verheijena, J.; Zwervera, S., et al. Exploring the relationships between landscape complexity, wild bee species richness and reproduction, and pollination services along a complexity gradient in the Netherlands. Biological Conservation, 214, 312-319, 2017. doi: 10.1016/j. biocon.2017.08.027

Caires, S. C.; Barcelos, D. Colapso das abelhas: Possíveis causas e consequências do seu desaparecimento na natureza. ACTA Apicola Brasilica, 5(1), 11, 2017. doi: 10.18378/aab. v5i1.5294

Calatayud-Vernich, P.; Calatayud, F.; Simó, E.; Picó, Y. Pesticide residues in honey bees, pollen and beeswax: Assessing beehive exposure. Environmental Pollution, 241, 106-114, 2018. doi: 10.1016/j.envpol.2018.05.062

Calderone, N. W.; Page, R. E. Effects of Interactions among Genotypically Diverse Nestmates on Task Specialization by Foraging Honey Bees (Apis mellifera). Behavioral Ecology and Sociobiology, 30(3/4), 219-226, 1992. Disponível em: $<$ https://www.jstor.org/stable/4600679>.

Carneiro, F.F.; Rigotto, R.M.; Augusto, L.G.S.; Friedrich, K.; Búrigo, A.C. (Orgs). Dossiê ABRASCO: um alerta sobre os impactos dos agrotóxicos na saúde. Rio de Janeiro: EPSJV, São Paulo: Expressão Popular, 2015. 
Céleres. Adoção de biotecnologia 2018/19: Análise Geral. INFORMATIVO BIOTECNOLOGIA IB19.01.2019. Disponível em: <http://www.celeres.com.br/wp-content/ uploads/2019/11/BoletimBiotecnologiaC\%C3\%A9leres_ Novembro2019-2.pdf $>$. Acesso em: ago. 2020.

Chiari, W. C.; Toledo, V. de A. A. de; Hoffmann-Campo, C. B. et al. Polinização por Apis mellifera em soja transgênica [Glycine max (L.) Merrill] Roundup Ready ${ }^{\mathrm{TM}}$ cv. BRS 245 RR e convencional cv. BRS 133. Acta Scientiarum - Agronomy, 30(2), 267-271, 2008. doi: 10.4025/actasciagron. v30i2.1787

Claudianos, C.; Ranson, H.; Johnson, R. M.; Biswas, S.; Schuler, M. A.; Berenbaum, M. R.; Feyereisen, R; Oakeshott, J. G. A deficit of detoxification enzymes: Pesticide sensitivity and environmental response in the honeybee. Insect Molecular Biology, 15(5), 615-636, 2006. doi: 10.1111/j.1365-2583.2006.00672.x

Connelly, H.; Poveda, K.; Loeb, G. Landscape simplification decreases wild bee pollination services to strawberry. $A g$ riculture, Ecosystems and Environment, 211, 51-56, 2015. doi: 10.1016/j.agee.2015.05.004

Cremer, S.; Armitage, S. A. O.; Schmid-Hempel, P. Social Immunity. Current Biology, 17(16), 693-702, 2007. doi: 10.1016/j.cub.2007.06.008

CTNBio - Comissão Técnica Nacional de Biossegurança. Resolução Normativa $\mathrm{N}^{\circ}$ 4, de 16 de agosto de 2007. Disponível em: $<$ http://ctnbio.mctic.gov.br/resolucoes-normativas $>$. Acesso em: mai. 2020.

Cunha, D. A. da S.; Nóbrega, M. A. dos S.; Antonialli Junior, W. F.. Insect Pollinators in Agricultural Systems. Ensaios e Ciência: Ciência Biológicas, Agrárias e da Saúde, 18(4), 185-194, 2014.

Dai, P-L.; Zhou, W.; Zhang, J.; Jiang, W-Y.; Wang, Q.; Cui, H-J.; Sun, J-H.; Wu, Y-Y, Zhou, T. The effects of Bt Cry1 Ah toxin on worker honeybees (Apis mellifera ligustica and Apis cerana cerana). Apidologie, 43, 384-391, 2012. doi: 10.1007/s13592-011-0103-z

De Mattos, I. M.; Soares, A. E. E.; Tarpy, D. R. Mitigating effects of pollen during paraquat exposure on gene expression and pathogen prevalence in Apis mellifera L. Ecotoxicology, 27(1), 32-44, 2018. doi: 10.1007/s10646-

\section{$017-1868-2$}

Desneux, N.; Decourtye, A.; Delpuech, J-M. The Sublethal Effects of Pesticides on Beneficial Arthropods. Annual Review of Entomology, 52(1), 81-106, 2007. doi: 10.1146/ annurev.ento.52.110405.091440

De Oliveira Diniz, T., Pereira, N. C., \& Gigliolli, A. A. S. Abelhas como bioindicadores ambientais. In: Oliveira-Junior, J. M. B.; Calvão, L. B. (Orgs) A interface do conhecimento sobre abelhas 2.- Ponta Grossa, PR: Atena, p. 10-18, 2020.

Di Prisco, G.; Cavaliere, V.; Annoscia, D.; et al. Neonicotinoid clothianidin adversely affects insect immunity and promotes replication of a viral pathogen in honey bees. Proceedings of the National Academy of Sciences, 110(46), 18466-18471, 2013. doi: 10.1073/pnas. 1314923110

Domingues, C. E.; Abdalla, F. C., Balsamo, P. J., Pereira, B. V., de Alencar Hausen, M., Costa, M. J., \& Silva-Zacarin, E. C. Thiamethoxam and picoxystrobin reduce the survival and overload the hepato-nephrocitic system of the Africanized honeybee. Chemosphere, 186, 994-1005, 2017. doi: 10.1016/j.chemosphere.2017.07.133

Do Prado, F. S. R., dos Santos, D. M., de Almeida Oliveira, T. M., Burgarelli, J. A. M., Castele, J. B., \& Vieira, E. M. Determination and uptake of abamectin and difenoconazole in the stingless bee Melipona scutellaris Latreille, 1811 via oral and topic acute exposure. Environmental Pollution, 265(1811), 114313, 2020. doi: 10.1016/j.envpol.2020.114313

Erler, S.; Moritz, R. F. A. Pharmacophagy and pharmacophory: mechanisms of self-medication and disease prevention in the honeybee colony (Apis mellifera). Apidologie, 47(3), 389-411, 2016. doi: 10.1007/s13592-015-0400-z

Evans, J. D., Aronstein, K., Chen, Y. P., Hetru, C., Imler, J. L., Jiang, H., Kanost, M., Thompson, G. J., Zou, Z., \& Hultmark, D. Immune pathways and defense mechanisms in honey bees Apis mellifera. Insect molecular biology, 15(5), 645-656, 2006. doi: 10.1111/j.1365-2583.2006.00682.x

Faita, M. R. Efeitos do herbicida Roundup ${ }^{\circledR}$ na sobrevivência e dinâmica de colônias de Apis mellifera. Florianópolis, Tese (Doutorado em Recursos Genéticos Vegetais) - UFSC, 2018. 
Faita, M. R. Conhecimento atual sobre o efeito da alimentação na saúde das abelhas. Zumzum, v. 374, n. 54, p. 4-6, 2020 .

Faita, M. R.; de Medeiros Oliveira, E., Júnior, V. V. A., Orth, A. I., \& Nodari, R. O. Changes in hypopharyngeal glands of nurse bees (Apis mellifera) induced by pollen-containing sublethal doses of the herbicide Roundup ${ }^{\circledR}$. Chemosphere, 211, 566-572, 2018. doi: 10.1016/j.chemosphere.2018.07.189

Faita, M. R.; Cardozo, M. M.; Amandio, D. T. T.; Orth, A. I.; \& Nodari, R. O. Glyphosate-based herbicides and Nosema sp. microsporidia reduce honey bee (Apis mellifera L.) survivability under laboratory conditions. Journal of Apicultural Research, 60, 1-11, 2020. doi: 10.1080/00218839.2020.1736782

Fearnside, P. M. Desmatamento na Amazônia brasileira: história, índices e consequências. Megadiversidade, 1(1), 113-123, 2005. Disponível em: $<$ http://inct-servamb.inpa. gov.br/publ_restritas/2019/Destruicao-v1/Cap-1-Desmatamento_historia-prova.pdf>

Fermino, F.; Penteado Falco, J. R.; De Alencar Arnaut De Toledo, V.; \& Colla Ruvolo-Takasusuki, M. C. Isoenzymes and cytochemical analysis in Tetragonisca angustula and Tetragonisca fiebrigi after herbicide contamination. Sociobiology, 58(2), 353-366, 2011.

Ferreira, P. A.; Boscolo, D.; Carvalheiro, L. G.; Biesmeijer, J. C.; Rocha, P. L.; \& Viana, B. F. Responses of bees to habitat loss in fragmented landscapes of Brazilian Atlantic Rainforest. Landscape Ecology, 30(10), 2067-2078, 2015. doi: 10.1007/s10980-015-0231-3

Freitas, B. M.; Imperatriz-Fonseca, V. L.; Medina, L. M.; Kleinert, A. D. M. P.; Galetto, L.; Nates-Parra, G.; \& Quezada-Euán, J. J. G. Diversity, threats and conservation of native bees in the Neotropics. Apidologie, 40(3), 332-346, 2009. doi: 10.1051/apido/2009012

Gallai, N.; Salles, J. M.; Settele, J.; \& Vaissière, B. E. Economic valuation of the vulnerability of world agriculture confronted with pollinator decline. Ecological Economics, 68(3), 810-821, 2009. doi: 10.1016/j.ecolecon.2008.06.014

Gallez, L.M.; Andrada, A.C.; Valle, A.F.; Gil, M.E.; Continanza, F.G. Polen de soja (Glycine max L.) en mieles del centro-oeste pampeano. $28^{\circ}$ Congreso Argentino de Producción Animal, Bahía Blanca, 19 - 21 de octubre de 2005. Revista Argentina de Producción Animal, 25, 398-399, 2005.

Gálvez-Mariscal, A. Detección de polen de plantas genéticamente modificadas en miel. Fase I. Universidad Nacional Autónoma de México. Facultad de Química. Informe final SNIB-CONABIO, proyecto KE007. México, D. F. 2013. 39p. Disponível em: $<$ https://www.researchgate.net/publication/263199853_Deteccion_de_polen_de_plantas_geneticamente_modificadas_en_miel_Fase_I $>$. Acesso em: ago. 2020.

Gamito, L. M.; Malerbo-Souza, D. T. Visitantes florais e produção de frutos em cultura de laranja (Citrus sinensis L. Osbeck). Acta Scientiarum. Animal Sciences, 28(4), 483-488, 2006. doi: 10.4025/actascianimsci.v28i4.612

Giannini, T. C.; Cordeiro, G. D.; Freitas, B. M.; Saraiva, A. M.; \& Imperatriz-Fonseca, V. L. The Dependence of Crops for Pollinators and the Economic Value of Pollination in Brazil. Journal of Economic Entomology, 108(3), 849-857, 2015a. doi: 10.1093/jee/tov093

Giannini, T. C.; Boff, S.; Cordeiro, G. D.; Cartolano, E. A.; Veiga, A. K.; Imperatriz-Fonseca, V. L.; \& Saraiva, A. M. Crop pollinators in Brazil: a review of reported interactions. Apidologie, 46(2), 209-223, 2015b. doi: 10.1007/ s13592-014-0316-z

Godfray, H. C. J.; Blacquiere, T.; Field, L. M. et al. A restatement of the natural science evidence base concerning neonicotinoid insecticides and insect pollinators A restatement of the natural science evidence base concerning neonicotinoid insecticides and insect pollinators. Proceedings of the Royal Society B: Biological Sciences, 281, 1-10, 2014. doi: 10.1098/rspb.2014.0558

Goulson, D. An overview of the environmental risks posed by neonicotinoid insecticides. Journal of Applied Ecology, 50(4), 977-987, 2013. doi: 10.1111/1365-2664.12111

Guillén, D.; Ginebreda, A.; Farré, M.; Darbra, R. M.; Petrovic, M.; Gros, M.; \& Barceló, D. Prioritization of chemicals in the aquatic environment based on risk assessment: Analytical, modeling and regulatory perspective. Science of the Total Environment, 440, 236-252, 2012. doi: 10.1016/j. scitotenv.2012.06.064 
Han, P.; Niu, C-Y.; Lei, C-L.; Cui, J-J.; Desneux, N. Quantification of toxins in a CrylAc + CpTI cotton cultivar and its potential effects on the honey bee Apis mellifera $\mathrm{L}$. Ecotoxicology, 19(8), 1452-9. 2010. doi: 10.1007/s10646010-0530-z.

Hanley, A; Huang, Z; Pett, W. Effects of dietary transgenic Bt corn pollen on larvae of Apis mellifera and Galleria mellonella. Jornal of Apicultura Research, 42(4), 77-81, 2003. doi: 10.1080/00218839.2003.11101097

Heard, T. A. The role of stingless bees in crop pollination. Annual Review of Entomology, 44(131), 183-206, 1999. doi: 10.1146/annurev.ento.44.1.183

Henry, M.; Beguin, M.; Requier, F.; et al. A common pesticide decreases foraging success and survival in honey bees. Science, 336(6079), 348-50, 2012. doi: 10.1126/ science. 1215039

Jia, Z.; Misra, H. P. Reactive oxygen species in in vitro pesticide-induced neuronal cell (SH-SY5Y) cytotoxicity: Role of NFאB and caspase-3. Free Radical Biology and Medicine, 42(2), 288-298, 2007. doi: 10.1016/j.freeradbiomed.2006.10.047

Kendall, R. J.; Anderson, T. A.; Baker, R. J. et al. Ecotoxicology. In: KLASSEN, Curtis D. (org.). Casarett \& Doull's Toxicology: The Basic Science of Poisons. 6. ed., p. 1013-1045, 2001.

Kennedy, C. M.; Lonsdorf, E., Neel, M. C. et al. A global quantitative synthesis of local and landscape effects on wild bee pollinators in agroecosystems. Ecology Letters, 16(5), 584-599, 2013.

Kesavachandran, C.; Singh, V. K.; Mathur, N. et al. Possible mechanism of pesticide toxicity-related oxidative stress leading to airway narrowing. Redox report: communications in free radical research, 11(4), 159-62, 2006. doi: 10.1179/135100006X116673

Klein, A. M.; Vaissiere, B. E.; Cane, J. H.; Steffan-Dewenter, I.; Cunningham, S. A.; Kremen, C., \& Tscharntke, T. Importance of pollinators in changing landscapes for world crops. Proceedings of the Royal Society B: Biological Sciences, 274(1608), 303-313, 2007. doi: 10.1098/rspb.2006.3721

Lamping, M. Shackles for Bees? The ECJ's Judgment on GMO-Contaminated Honey. European Journal of Risk Regulation, 3(01), 123-129. 2012. doi: 10.1017/ s1867299x00001926

Leite, D. T.; Sampaio, R. B.; dos Santos, C. O.; dos Santos, J. N.; Chambó, E. D.; de Carvalho, C. A. L.; \& da Silva Sodré, G. Toxicity of fenpyroximate, difenoconazole and mineral oil on Apis mellifera L. Sociobiology, 65(4), 737-743, 2018. doi: 10.13102/sociobiology.v65i4.3416

Lima, C. S. S.; Pires, R. N. C.; Guedes, E. Y. T.; Nakasu, M. S.; Lara, E. M. G.; Fontes, E. R.; Sujii, S. C. Dias \& L. A. O. Campos. Does Cry1 Ac Bt-toxin impair development of worker larvae of Africanized honey bee. Journal of Applied Entomology,135, 415-422, 2010. doi: 10.1111/j.14390418.2010.01573.xC

Malerbo-Souza, D. T.; Nogueira-Couto, R. H.; Couto, L. A. Polinização em cultura de laranja Citrus Pollination in orange sweet crop (Citrus sinensis L). Animal Science, 40(4), 237-242, 2003. doi: 1 0.1590/S1413-95962003000400001

Malerbo-Souza, D. T.; Halak, A. L. Comportamento de forrageamento de abelhas e outros insetos nas panículas da mangueira (Mangifera indica L.) e produção de frutos. Acta Scientiarum - Animal Sciences, 31(3), 335-341, 2009. doi: 10.4025/actascianimsci.v31i3.6678

Malone, L.; Pham-Dèlègue, M. Effects of transgene products on honey bees (Apis mellifera) and bumblebees (Bombus sp.). Apidologie, 32, 287-304, 2001. doi: 10.1051/ apido:2001130

Malone, L. A., Scott-Dupree, C. D., Todd, J. H., \& Ramankutty, P. No sub-lethal toxicity to bumblebees, Bombus terrestris, exposed to bt-corn pollen, captan and novaluron. New Zealand Journal of Crop and Horticultural Science, 35(4), 435-439, 2007. doi: 10.1080/01140670709510211

MapBiomas. Revelando o uso da terra com ciência e transparência. Coleção 5. 2020. Disponível em: <https:// mapbiomas.org/noticias>. Acesso em: ago. 2020.

Matin, G.; Kargar, N.; Buyukisik, H. B. Bio-monitoring of cadmium, lead, arsenic and mercury in industrial districts of Izmir, Turkey by using honey bees, propolis and pine tree leaves. Ecological Engineering, 90, 331-335, 2016. doi: 10.1016/j.ecoleng.2016.01.035 
Meehan, T. D., Werling, B. P., Landis, D. A., \& Gratton, C. Agricultural landscape simplification and insecticide use in the Midwestern United States. Proceedings of the National Academy of Sciences of the United States of America, 108(28), 11500-11505, 2011. doi: 10.1073/ pnas. 1100751108

Mesquita, B. A. de. Demanda por alimentos e as consequências na Amazônia brasileira "sucesso" do agronegócio e tragédia do desmatamento. $12^{a}$ Encuentro de Geógrafos de América Latina; Montevidéu, Uruguai, 2009. Disponível em: $<$ http://www.observatoriogeograficoamericalatina.org. $\mathrm{mx} /$ egal12/Procesosambientales/Impactoambiental/81.pdf $>$

Michener, C. D. The bees of the world. The Johns Hopkins University Press. 2ed. 2007.

Moritz, R. F. A.; Fuchs, S. Organization of honeybee colonies: Characteristics and consequences of a superorganism concept. Apidologie, 29(1-2), 7-21, 1998. doi: 10.1051/ apido:19980101

Morse, R. A.; Calderone, N. W. The value of honey bees as pollinators of US crops in 2000. Bee Culture, 128(3), 1-15, 2000. Disponível em: $<$ https://citeseerx.ist.psu.edu/viewdoc/download?doi=10.1.1.554.5898\&rep=rep1\&type=pdf $>$

Moure, J. S.; Urban, D.; Melo, G. A. R. Catalogue of the bees (Hymenoptera, Apoidea) in the Neotropical region. Curitiba, PR: Sociedade Brasileira de Entomologia, 2007.

Mullin, C. A., Frazier, M., Frazier, J. L., Ashcraft, S., Simonds, R., \& Pettis, J. S. High Levels of Miticides and Agrochemicals in North American Apiaries: Implications for Honey Bee Health. PLoS ONE, 5(3), 2010. doi: 10.1371/ journal.pone.0009754

Mullin, C. A., Fine, J. D., Reynolds, R. D., \& Frazier, M. T. Toxicological Risks of Agrochemical Spray Adjuvants: Organosilicone Surfactants May Not Be Safe. Frontiers in Public Health, 4(92), 1-8, 2016. doi: 10.3389/ fpubh.2016.00092

Nacci, D. E.; Cayula, S.; Jackim, E. Detection of DNA damage in individual cells from marine organisms using the single cell gel assay. Aquatic Toxicology, 35(3-4), 197-210, 1996. doi: 10.1016/0166-445X(96)00016-1

Nascimento, W. M.; Batista, E. A.; Freitas, R. A. Utiliza- ção de agentes polinizadores na produção de sementes de cenoura e pimenta doce em cultivo protegido. Horticultura Brasileira, 30, 494-498, 2012. doi: 10.1590/S010205362012000300023

Negri, P.; Villalobos, E.; Szawarski, N., et al. Towards precision nutrition: A novel concept linking phytochemicals, immune response and honey bee health. Insects, 10(11), 401-430, 2019. doi: 10.3390/insects 10110401

Nodari, R. O.; Guerra, M. P. A agroecologia: Estratégias de pesquisa e valores. Estudos Avançados, 29(83), 183-207, 2015. doi:10.1590/S0103-40142015000100010.

Nocelli, R. C. F.; Soares, S. M. M.; Monquero, P. A. Effects of Herbicides on the survival of the Brazilian native bee Melipona scutellaris Latreille, 1811 (HYMENOPTERA: APIDAE). Planta Daninha, 37, p. e019220193, 2019. doi: 10.1590/S0100-83582019370100

Novais, S. M. A.; Nunes, C. A.; Santos, N. B., et al. Effects of a possible pollinator crisis on food crop production in Brazil. PLoS ONE, 11(11), 1-12, 2016. doi: 10.1371/journal. pone.0167292

Oldroyd, B. What's Killing American Honey Bees? PLOS Biology, 5(6): e-168. 2007. doi: 10.1371/journal. pbio. 0050168

Pettis, J. S.; Lichtenberg, E. M.; Andree, M.; Stitzinger, J.; Rose, R.; \& van Engelsdorp, D. Crop pollination exposes honey bees to pesticides which alters their susceptibility to the gut pathogen Nosema ceranae. PLoS ONE, 8(7), e70182. 2013. doi: 10.1371/journal.pone.0070182

Pignati, W. A.; Machado, J. M. H.; Pena, P. G. L. O agronegócio e seus impactos na saúde dos trabalhadores e da população do estado de Mato Grosso. In: Gomez, C. M.; Machado, J. M. H.; Pena, P. G. L. (orgs.). Saúde do trabalhador na sociedade brasileira contemporânea. Rio de Janeiro: Editora Fiocruz, 2011, p. 245-272. Disponível em: <http:// books.scielo.org/id/qq8zp/pdf/minayo-9788575413654-13. pdf $>$

Pignati, W. A.; Lima, F. A. N. D. S.; Lara, S. S. D.; Correa, M. L. M.; Barbosa, J. R.; Leão, L. H. D. C., \& Pignatti, M. G. Distribuição espacial do uso de agrotóxicos no Brasil: uma ferramenta para a Vigilância em Saúde. Ciência \& Saúde Coletiva, 22(10), 3281-3293, 2017. doi: 10.1590/1413- 


\subsection{7}

Pinheiro-Machado, C.; Santos, I. A. dos; Imperatriz-Fonseca, V. L.; Kleinert, A. M. P.; Silveira, F. A. da. Brazilian bee surveys: state of knowledge, conservation and sustainable use. In: Kevan, P., Imperatriz Fonseca, V. L. (ed.) The Conservation Link Between Agriculture and Nature. Brasília, DF: Ministry of Environment, p. 115-129, 2002.

Pinheiro, M.; Gaglianone, M. C.; Nunes, C. E. P.; Sigrist, M. R., \& Santos, I. D. Polinização por abelhas. In: Rech, A. R., Agostini, K., Oliveira, P.E., Machado I. C. (orgs.) Biologia da polinização. Brasília, DF: Ministério do Meio Ambiente, p. 205-234, 2014.

Porto, M. F.; Soares, W. L. Modelo de desenvolvimento, agrotóxicos e saúde: um panorama da realidade agrícola brasileira e propostas para uma agenda de pesquisa inovadora. Revista brasileira de Saúde Ocupacional, 37(125), 17-31, 2012. doi: 10.1590/S0303-76572012000100004.

Potts, S. G. Biesmeijer; J. C., Kremen, C.; Neumann, P.; Schweiger, O.; \& Kunin, W. E. Global pollinator declines: Trends, impacts and drivers. Trends in Ecology and Evolution, 25(6), 345-353, 2010. doi: 10.1016/j.tree.2010.01.007

Prado, A.; Pioz, M.; Vidau, C., et al. Exposure to pollen-bound pesticide mixtures induces longer-lived but less efficient honey bees. Science of the Total Environment, 650, 1250-1260, 2019. doi: 10.1016/j.scitotenv.2018.09.102

Ramirez-Romero, R.; Chaufaux, J.; Pham-Delègue, M. H. Effects of Cry $1 \mathrm{Ab}$ protoxin, deltamethrin and imidacloprid on the foraging activity and the learning performances of the honeybee Apis mellifera, a comparative approach. Apidologie, 36(4), 601-611, 2005. doi: 10.1051/apido:2005039

Ramirez-Romero, R.; Desneux, N., Decourtye, A., Chaffiol, A., \& Pham-Delègue, M. H. Does Cry1 Ab protein affect learning performances of the honey bee Apis mellifera L. (Hymenoptera, Apidae)? Ecotoxicology and Environmental Safety, 70(2), 327-333, 2008. doi: 10.1016/j. ecoenv.2007.12.002

Roubik, D. W. Feral African Bees Augment Neotropical Coffee Yield. In: Kevan, P., Imperatriz Fonseca, V. L. (ed.) The Conservation Link Between Agriculture and Nature. Brasília, DF: Ministry of Environment, 2002, p.255-266.
Rubio, F.; Guo, E.; Kamp, L. Survey of Glyphosate Residues in Honey, Corn and Soy Products. Environmental \& Analitical Toxicology, 5(1), 249, p.1-8, 2014. doi: 10.4172/21610525.1000249

Sabugosa-Madeira, B.; Abreu, I.; Ribeiro, H.; Cunha, M. Bt transgenic maize pollen and the silent poisoning of the hive. Journal of Apicultural Research, 46(1), 57-58, 2007. doi:10.1080/00218839.2007.11101367

Sánchez-Bayo, F. Goulson, D., Pennacchio, F., Nazzi, F., Goka, K., \& Desneux, N. Are bee diseases linked to pesticides? - A brief review. Environment International, 89-90, 7-11, 2016. doi: 10.1016/j.envint.2016.01.009

Sánchez-Bayo, F.; Goka, K. Pesticide residues and bees - A risk assessment. PLoS ONE, 9(4), e94482, 2014. doi:10.1371/journal.pone.0094482

Santos-Filho, E.; Silva, R. D. S.; Barretto, H. H.; Inomata, O. N.; Lemes, V. R.; Kussumi, T. A.; \& Rocha, S. O. Grau de exposição a praguicidas organoclorados em moradores de aterro a céu aberto. Revista de Saude Publica, 37(4), 515-522, 2003. doi: 10.1590/S0034-89102003000400018

Santos, J. A. Resgate de abelhas nativas sem ferrão como proposta de mitigação de impactos ambientais. Curitiba, Monografia (Especialização em Análise Ambiental) - UFPR, 2015.

Schmaranzer, S. Thermoregulation of water collecting honey bees (Apis mellifera). Journal of Insect Physiology, 46(8), 1187-1194, 2000. doi: 10.1016/S0022-1910(00)00039-1

Seide, V. E.; Bernardes, R. C.; Pereira, E. J. G.; Lima, M. A. P. Glyphosate is lethal and Cry toxins alter the development of the stingless bee Melipona quadrifasciata. Environmental Pollution, 243, 1854-1860, 2018. doi:10.1016/j. envpol.2018.10.020

Sperb, P. Laudo mostra que agrotóxicos causaram morte de milhões de abelhas. Folha de São Paulo, Porto Alegre, 24 jul. 2019. Disponível em: $<$ https://www1.folha.uol.com. br/ambiente/2019/07/laudo-mostra-que-agrotoxicos-causaram-morte-de-milhoes-de-abelhas.shtml >. Acesso em: jan. 2021.

Silva, W. P.; Paz, J. R. L. Abelhas sem ferrão: muito mais do que uma importância econômica. Natureza on line, 10(3), 
146-152, 2012.

Souza, D. L.; Evangelista-Rodrigues, A.; Caldas Pinto, M. do S. de. As Abelhas Como Agentes Polinizadores REDVET- Revista Electrónica de Veterinaria, VIII(3), 1-7, 2007.

Tadei, R.; Aparecido J.; Silva-Zacarin, E. C. M. Efeitos tardios da co-exposição larval a doses realísticas do inseticida clotianidina e do fungicida piraclostrobina: avaliação da longevidade das operárias adultas de Apis mellifera africanizada. In: Jornadas de Jóvenes Investigadores AUGM, $26^{\circ}$, Mendoza, Argentina, 2018. Disponível em: $<$ https:// librosffyl.bdigital.uncu.edu.ar/objetos_digitales/12943/ tadei-rafaela-ufscar.pdf $>$.

Theodorakis, C. W.; Shugart, L. R. Genetic ecotoxicology III: The relationship between DNA strand breaks and genotype in mosquito fish exposed to radiation. Ecotoxicology, 7(4), 227-236, 1998. doi: 10.1023/A:1008990828651

Thompson, H. M.; Levine, S. L.; Doering, J.; Norman, S.; Manson, P.; Sutton, P.; \& von Mérey, G. Evaluating exposure and potential effects on honeybee brood (Apis mellifera) development using glyphosate as an example. Integrated Environmental Assessment and Management, 10(3), 463-470, 2014. doi: 10.1002/ieam.1529

Tiedje, J.M.; Colwell, R.K.; Grossman, Y. L.; Hodson, R.E.; Lenski, R.E; Mack, R.N.; Regal, P.J. The planned introduction of genetically engineered organisms - Ecological considerations and recommendations. Ecology, 70(2), 298-315, 1989. doi: 10.2307/1937535

Toledo, V. A. A.; Halak, A. L.; Chambó, E. D.; Baitala, T. V.; Costa-Maia, F. M.; \& Malerbo-Souza, D. T. Polinização por Abelhas (Apis mellifera L.) em Laranjeira (Citrus sinensis L. Osbeck). Scientia Agraria Paranaensis, 12(4), 236-246, 2013. doi: 10.18188/1983-1471/sap.v12n4p236-246

Tomé, H. V. V.; Ramos, G. S.; Araújo, M. F.; et al. Agrochemical synergism imposes higher risk to neotropical bees than to honeybees. Royal Society Open Science, 4: 160866, 2017. doi: 10.1098/rsos.160866

Tope, A.; Bebe, F. N.; Panemangalore, M. Micronuclei frequency in lymphocytes and antioxidants in the blood of traditional limited-resource farm workers exposed to pesticides. Journal of environmental science and health. Part. $B$, Pesticides, food contaminants, and agricultural wastes,
41(6), 843-53, 2006. doi: 10.1080/03601230600805907

Trevisan, H.; Aguiar, A.; Sabugosa-Madeira, B., et al. Análise do efeito do pólen do milho transgênico resistente a insetos sobre o desenvolvimento de Galleria mellonella (Fabricius, 1754) (Lepidoptera, Pyralidae) e possíveis consequências ecológicas. Bioscience Journal, 29(4), 796804, 2013.

Vandenberg, J. D. Safety of four entomopathogens for caged adult honey bees (Hymenoptera: Apidae). Journal of Economic Entomology, 83(3), 755-759. 1990. doi: 10.1093/ jee/83.3.755

Vandenberg, J. D.; Shimanuki, H. Viability of Bacillus thuringiensis and its efficacy for larvae of the greater wax moth (Lepidoptera: Pyralidae) following storage of treated combs. Journal of Economic Entomology, 83, 760-765, 1990. doi: $10.1093 /$ jee $/ 83.3 .760$

Vieira, M. F.; Fonseca, R. S. Biologia reprodutiva em angiospermas: síndromes florais, polinizações e sistemas reprodutivos sexuados. Viçosa, MG: Ed. UFV, 2014. Disponível em: <https://www2.cead.ufv.br/serieconhecimento/ wp-content/uploads/2015/05/biologia-reprodutiva.pdf $>$.

Villanueva-Gutiérrez, R.; Echazarreta-González, C.; Roubik, D.; Moguel-Ordóñez, B. Y. Transgenic soybean pollen (Glycine max L.) in honey from the Yucatán peninsula, Mexico. Scientific Reports, 4, 4022, 2014. doi: 10.1038/ srep04022

Whitehorn, P. R.; O’Connor, S.; Wackers, F. L.; Goulson, D. Neonicotinoid Pesticide Reduces Bumble Bee Colony Growth and Queen Production. Science, 336(6079), 351-352, 2012. doi: 10.1126/science. 1215025

Woodcock, B. A.; Bullock, J. M.; Shore, R. F.; et al. Country-specific effects of neonicotinoid pesticides on honey bees and wild bees. Science, 356(6345), 1393-1395, 2017. doi: 10.1126/science.aaa1190

Zaluski, R.; Justulin, L. A.; Orsi, R. de O. Field-relevant doses of the systemic insecticide fipronil and fungicide pyraclostrobin impair mandibular and hypopharyngeal glands in nurse honeybees (Apis mellifera). Scientific Reports, 7(1), 15217, 2017. doi: 10.1038/s41598-017-15581-5

Zaluski, R.; Bittarello, A. C.; Vieira, J. C. S.; et al. Mod- 
ification of the head proteome of nurse honeybees (Apis mellifera) exposed to field-relevant doses of pesticides. Scientific Reports, 10(1), 1-11, 2020. doi: 10.1038/s41598020-59070-8

Zayed, A. Bee genetics and conservation. Apidologie, 40(3), 237-262, 2009. doi: 10.1051/apido/2009026

Zhu, W.; Schmehl, D. R.; Mullin, C. A.; Frazier, J. L. Four common pesticides, their mixtures and a formulation solvent in the hive environment have high oral toxicity to honey bee larvae. PLoS ONE, 9(1), e77547, 2014. doi: 10.1371/ journal.pone. 0077547 